\title{
Dendritic Excitability of Mouse Frontal Cortex Pyramidal Neurons Is Shaped by the Interaction among HCN, Kir2, and $\mathrm{K}_{\text {leak }}$ Channels
}

\author{
Michelle Day, David B. Carr, Sasha Ulrich, Ema Ilijic, Tatiana Tkatch, and D. James Surmeier \\ Department of Physiology, Northwestern University Medical School, Chicago, Illinois 60611
}

\begin{abstract}
Dendritically placed, voltage-sensitive ion channels are key regulators of neuronal synaptic integration. In several cell types, hyperpolarization/cyclic nucleotide gated (HCN) cation channels figure prominently in dendritic mechanisms controlling the temporal summation of excitatory synaptic events. In prefrontal cortex, the sustained activity of pyramidal neurons in working memory tasks is thought to depend on the temporal summation of dendritic excitatory inputs. Yet we know little about how this is accomplished in these neurons and whether HCN channels play a role. To gain a better understanding of this process, layer V-VI pyramidal neurons in slices of mouse prelimbic and infralimbic cortex were studied. Somatic voltage-clamp experiments revealed the presence of rapidly activating and deactivating cationic currents attributable to $\mathrm{HCN} 1 / \mathrm{HCN} 2$ channels. These channels were open at the resting membrane potential and had an apparent half-activation voltage near $-90 \mathrm{mV}$. In the same voltage range, $\mathrm{K}^{+}$currents attributable to Kir2.2/2.3 and $\mathrm{K}^{+}$-selective leak $\left(\mathrm{K}_{\text {leak }}\right)$ channels were prominent. Computer simulations grounded in the biophysical measurements suggested a dynamic interaction among Kir2, $\mathrm{K}_{\text {leak }}$, and $\mathrm{HCN}$ channel currents in shaping membrane potential and the temporal integration of synaptic potentials. This inference was corroborated by experiment. Blockade of Kir $2 / \mathrm{K}_{\text {leak }}$ channels caused neurons to depolarize, leading to the deactivation of HCN channels, the initiation of regular spiking $(4-5 \mathrm{~Hz})$, and enhanced temporal summation of EPSPs. These studies show that HCN channels are key regulators of synaptic integration in prefrontal pyramidal neurons but that their functional contribution is dependent on a partnership with Kir2 and $\mathrm{K}_{\text {leak }}$ channels.
\end{abstract}

Key words: voltage clamp; prefrontal cortex; hyperpolarization-activated cation current; inward rectifier; single-cell RT-PCR; whole-cell recording; KCNK

\section{Introduction}

Pyramidal neurons in the prefrontal cortex (PFC) are thought to be key elements in the neural circuitry underlying a variety of important cognitive functions (Fuster, 1997; Goldman-Rakic, 1999). One of these functions is working memory. The mechanisms that enable sustained neural activity thought to be critical to this function are essentially unknown. One important factor undoubtedly is the strong recurrent excitatory synaptic connections within the PFC that promote sustained activity (McCormick et al., 2002). However, it is also highly likely that the pyramidal neurons themselves have intrinsic mechanisms that support sustained activity. Studies of neurons in other regions have revealed that the somatodendritic membrane on which synaptic contacts are made is richly invested with ionic conductances that shape how this input is integrated and translated into spiking

Received Feb. 16, 2005; revised Aug. 9, 2005; accepted Aug. 9, 2005.

This work was supported by National Institutes of Health Grant MH62070. We thank Joshua Held for his help with the computer modeling work, Karen Brunell for her assistance with PCR, and Dr. C. Savio Chan and Quin Ruan for their skilled assistance with histology.

Correspondence should be addressed to D. James Surmeier, Department of Physiology, Northwestern University Medical School, 303 East Chicago Avenue, Chicago, IL 60611. E-mail: j-surmeier@northwestern.edu. D0I:10.1523/JNEUROSCI.2650-05.2005

Copyright $\odot 2005$ Society for Neuroscience $\quad$ 0270-6474/05/258776-12\$15.00/0
(Schwindt and Crill, 1995; Stuart and Sakmann, 1995; Magee et al., 1998; Hausser et al., 2000; Takigawa and Alzheimer, 2002).

One of the most important channels governing synaptic integration in pyramidal neurons in other regions is the hyperpolarization/cyclic nucleotide gated $(\mathrm{HCN})$ cation channel (Pape, 1996; Luthi and McCormick, 1998; Magee, 1998). In CA1 pyramidal neurons, $\mathrm{HCN}$ channels are determinants of the resting membrane potential, input resistance, and membrane time and length constants. Their density appears to increase with distance from the soma, placing them in a strategic position to interact with synaptically generated events. Perhaps the bestcharacterized role of HCN channels in these neurons is in the regulation of synaptic integration (Magee, 1999). Deactivation of HCN channel currents produces a sublinear summation of EPSPs at hyperpolarized membrane potentials. This action depends not only on kinetic properties of the HCN channels involved but on them being active in the voltage range in which the EPSPs are being generated. Both properties are governed by the molecular composition of the channel (Santoro et al., 2000). The work presented here suggests that HCN channels in deep-layer pyramidal neurons of the rodent homolog of the PFC subserve a similar function.

Yet how do HCN channels stay activated so that they can shape synaptic integration? If unopposed, they will shut them- 
selves off by depolarizing the membrane. Preventing HCN deactivation requires the presence of a countervailing, noninactivating channel that hyperpolarizes the membrane potential. The experiments described here suggest that dendritically positioned, constitutively active, inwardly rectifying Kir2.2/ $2.3 \mathrm{~K}^{+}$channels and $\mathrm{K}^{+}$-selective leak $\left(\mathrm{K}_{\text {leak }}\right)$ channels subserve this function in deep-layer pyramidal neurons found in the mouse homolog of the PFC [prelimbic and infralimbic (PrL/IL) pyramidal neurons (PPNs)]. By balancing their contribution to synaptic integration, these two $\mathrm{K}^{+}$channels appear to effectively enable $\mathrm{HCN}$ channels to regulate the temporal summation of EPSPs in isolation at membrane potentials near those found in awake animals. However, the molecular composition of these channels makes it likely that this partnership is regulated by neuromodulators known to shape cortical function.

\section{Materials and Methods}

Brain slice preparation. Coronal slices containing the PrL/IL cortex, 275 $\mu \mathrm{m}$ thick, were obtained from 19- to 25-d-old C57BL/6 mice (Harlan Sprague Dawley, Madison, WI). The mice were anesthetized with isoflurane (Baxter, Deerfield, IL) and decapitated. Brains were rapidly removed and sectioned in oxygenated, ice-cold, artificial CSF (ACSF) using a Leica (Wetzlar, Germany) VT1000S vibratome. The ACSF contained the following (in mM): $124 \mathrm{NaCl}, 3 \mathrm{KCl}, 2.4 \mathrm{CaCl}_{2}, 1.2 \mathrm{MgCl}_{2}, 26$ $\mathrm{NaHCO}_{3}, 1 \mathrm{NaH}_{2} \mathrm{PO}_{4}$, and $10 \mathrm{D}-(+)$-glucose. Unless otherwise noted, all chemicals and reagents were obtained from Sigma (St. Louis, MO). The slices were transferred to a holding chamber in which they were incubated in ACSF at $35^{\circ} \mathrm{C}$ for $1 \mathrm{~h}$, after which they were stored at room temperature until whole-cell recording or single-cell harvesting for single-cell reverse-transcription PCR (scRT-PCR) experiments (1-4 h). The external ACSF solutions were bubbled with $95 \% \mathrm{O}_{2} / 5 \% \mathrm{CO}_{2}$ at all times to maintain oxygenation and a $\mathrm{pH} \approx 7.4$.

Whole-cell recordings. Whole-cell voltage-clamp and current-clamp recordings were performed using standard techniques. Slices were transferred to a submersion-style recording chamber mounted on an Olympus Optical (Melville, NY) BX50WI microscope. The slices were continuously perfused with $\approx 1.5 \mathrm{ml} / \mathrm{min}$ ACSF and maintained at $32-33^{\circ} \mathrm{C}$ with a Warner Instruments (Hamden, CT) TC-324B inline heater. Deeplayer (V-IV) PPNs were visually identified by both topology and morphology using infrared-differential interference contrast video microscopy with a Hamamatsu (Hamamatsu, Japan) C2400 Newvicon camera/ controller system. Patch electrodes were made by pulling BF150-86-10 glass on a P-97 Flaming/Brown micropipette puller (both from Sutter Instruments, Novato, CA). The pipette solution contained the following (in mM): $135 \mathrm{KMeSO}_{4}$ (ICN Biomedicals, Aurora, $\mathrm{OH}$ ), $5 \mathrm{KCl}, 0.5 \mathrm{CaCl}_{2}$, 5 HEPES, 5 EGTA, 2 MgATP, $0.2 \mathrm{Na}_{2} \mathrm{GTP}, 0.1$ spermine, and $0.1 \%$ biocytin, $\mathrm{pH} 7.25-7.3$ with $\mathrm{KOH}(270 \mathrm{mOsm} / \mathrm{l})$. Spermine was routinely included in the internal solutions to prevent rundown of the inwardly rectifying $\mathrm{K}^{+}$currents (Ficker et al., 1994). As measured in the bath, the pipette resistance was $\sim 4 \mathrm{M} \Omega$. Electrophysiological recordings were obtained using an Axopatch 700A amplifier, a Digidata 1322A 16-bit data acquisition system, and pClamp software version 8.2 (Molecular Devices, Union City, CA). Gigaohm seals were formed in voltage-clamp mode on the cell somas. After patch rupture, series resistance decreased to between 10 and $15 \mathrm{M} \Omega$; in voltage-clamp experiments, it was electronically compensated $(50-70 \%)$. Records were not corrected for the liquid junction potential, which was estimated to be $6-7 \mathrm{mV}$.

The channel blockers tetrodotoxin (TTX) (Alomone Labs, Jerusalem, Israel), CNQX, $\mathrm{BaCl}_{2}$, and ZD-7288 (4-ethylphenylamino-1,2-dimethyl6-methylaminopyrimidinium chloride) (Tocris Cookson, Ellisville, $\mathrm{MO}$ ) were prepared as concentrated stocks in distilled water and either frozen until use or freshly added to the external solution.

Data were analyzed with ClampFit version 8.2 (Molecular Devices) and/or IGOR version 4.05 (WaveMetrics, Lake Oswego, OR). Pooled data are graphical presented as either means \pm SE or box plots. In the box plots, the median is represented by the central bar. The outer edges of the box split the upper and lower halves of the data in half again (interquar- tile range). Finally, the whiskers delineate the upper and lower outerquartiles of the data (Systat version 5.2; Systat, Evanston, IL).

Computer simulation/modeling. Simulations were performed using NEURON (version 5.7) (Hines and Carnevale, 2001). PPNs were modeled using a cylindrical soma ( $35 \mu \mathrm{m}$ length, $25 \mu \mathrm{m}$ diameter) with a single bifurcating apical dendrite and two basal dendrites. Each basal dendrite was $300 \mu \mathrm{m}$ in length, having a diameter of $1.2 \mu \mathrm{m}$ near the soma and decreasing linearly to $0.5 \mu \mathrm{m}$. The apical dendrite had three compartments: a proximal compartment ( $400 \mu \mathrm{m}$ in length, $4.2 \mu \mathrm{m}$ diameter at the soma, tapering to $3.9 \mu \mathrm{m}$ at the bifurcation) and two secondary compartments $(400 \mu \mathrm{m}$ in length, $2.6 \mu \mathrm{m}$ diameter at the bifurcation, tapering to $1.6 \mu \mathrm{m})$. Each dendritic compartment could be described as the frustum of a cone. Specific membrane capacitance (1 $\left.\mu \mathrm{F} / \mathrm{cm}^{2}\right)$ and axial resistivity $(250 \Omega / \mathrm{cm})$ were the same for all compartments. A somatic electrode was "attached" to the model to simulate current- and voltage-clamp recordings.

To model currents generated from somatic point-clamp recordings, "canonical" allosteric models of HCN1 and HCN2/HCN1 channels were derived from published data (Chen et al., 2001). Because ambient cAMP levels were assumed to be low, the models were simplified to reflect the unmodulated, closed to open transition. HCN current traces generated experimentally by somatic voltage steps delivered to PPNs in tissue slices were imported from Igor Pro to the Neuron Multi-Run Fitter (MRF). The HCN density was assumed to be zero in the somatic compartment and to increase by a factor of 10 from the proximal edge of the dendritic compartment to the first bifurcation of the apical dendrite or to the end of the basal dendrites (Magee, 1998). MRF was allowed to vary the HCN density given this constraint. The MRF also was allowed to change gating parameters to fit the experimentally derived currents. This approach led to a reasonably accurate simulation of the experimental data with a single channel type. The forward and backward rate constants for the HCN model were, respectively, as follows: $a=a 0 \times Q_{10} /\left\{1+\exp \left(\left(V_{\mathrm{m}}-\right.\right.\right.$ $a h) / a c)\}$ and $b=b 0 \times Q_{10} /\left\{1+\exp \left(\left(V_{\mathrm{m}}-b h\right) / b c\right)\right\}$, where $Q_{10}=4$, $a 0=0.037 \mathrm{~ms}^{-1}, a h=-110.7 \mathrm{mV}, a c=8 \mathrm{mV}, b 0=0.22 \mathrm{~ms}^{-1}, b h=$ $-22.7 \mathrm{mV}$, and $b c=-15 \mathrm{mV}$. The gating properties resemble those of HCN2/HCN1 heteromeric channels reported by Chen et al. (2001). In EPSP simulations, the HCN density was assumed to increase from $3 e-5$ to $3 e-4 \mathrm{~S} / \mathrm{cm}^{2}$ at the branch point or tips of the basal dendrites.

The Kir2 channels were simulated using a formalism that allowed the rectification of the channel to be recreated: $I=G_{\text {kir }} \times\left(V_{\mathrm{m}}-E_{\mathrm{K}}\right)$ and $G_{\text {kir }}=G_{\text {max }} /\left(1+\exp \left(\left(V_{\mathrm{m}}-K 1\right) / K 2\right)\right)$, where $I$ is current, $V_{\mathrm{m}}$ is the membrane potential, $E_{\mathrm{K}}$ is the $\mathrm{K}^{+}$equilibrium potential, $G_{\mathrm{kir}}$ is the Kir conductance, $G_{\max }$ is the maximum conductance, and $K 1$ and $K 2$ are constants. As with $\mathrm{HCN}$ currents, $\mathrm{Ba}^{2+}$-sensitive $\mathrm{K}^{+}$currents recorded from PPNs were imported to Neuron in an attempt to recreate the experimental situation. Currents blocked by low $(50 \mu \mathrm{M})$ and high $(200$ $\mu \mathrm{M}) \mathrm{Ba}^{2+}$ concentrations suggested that the currents were best described by a sum of Kir2 and $\mathrm{K}_{\text {leak }}$ channels $\left[I=G_{\text {leak }} \times\left(V_{\mathrm{m}}-E_{\mathrm{K}}\right)\right]$. Using a uniform distribution of Kir2 and $K_{\text {leak }}$ channels, the somatic point-clamp data could be accurately reproduced. Fitting was not strongly affected by this distribution assumption. Parameters for the Kir2 channel $\left(G_{\mathrm{kir}}=\right.$ $6 e-5 \mathrm{~S} / \mathrm{cm}^{2}, K 1=-90 \mathrm{mV}$, and $\left.K 2=12.1 \mathrm{mV}\right)$ and $\mathrm{K}_{\text {leak }}\left(G_{\text {leak }}=6 e-6\right.$ $\mathrm{S} / \mathrm{cm}^{2}$ ) estimated from these experiments were used in subsequent simulations.

EPSPs were generated at a point three-quarters of the way to the branch point in the apical dendrite using Neuron utilities. The EPSPs had conductance rise time of $0.2 \mathrm{~ms}$, a decay time constant of $1 \mathrm{~ms}$, and a maximal conductance of $3 e-9 \mathrm{~S}$.

Histology. Biocytin-filled PPNs were visualized using the ABC-3, 3-diaminobenzidine tetrahydrochloride (DAB) method as described previously (Horikawa and Armstrong, 1988) with some modifications. After electrophysiological recording, the slices were fixed overnight at $4^{\circ} \mathrm{C}$ in a solution containing $4 \%$ paraformaldehyde and $15 \%$ picric acid in $0.1 \mathrm{M}$ phosphate buffer, $\mathrm{pH}$ 7.4. The slices were reacted in a 1:100 dilution of avidin-biotin complex conjugated to horseradish peroxidase for $2 \mathrm{~h}$ at room temperature (ABC Elite kit; Vector Laboratories, Burlingame, CA). Next, they were incubated in $0.1 \mathrm{~m}$ Tris-buffered saline solution containing $0.025 \% \mathrm{DAB}, 0.05 \%$ nickel chloride, and $0.006 \%$ hydrogen peroxide. The slices were then temporarily mounted and 
coverslipped, and the biocytin-positive neurons were examined and photographed.

$R T$-PCR. Individual cells were harvested for scRT-PCR as described previously (Surmeier et al., 1995; Day et al., 2002). The deep layers V and VI of the PrL/IL cortex were dissected from the slices and transferred to oxygenated HEPES-buffered HBSS containing $1 \mathrm{mg} / \mathrm{ml}$ protease (type $\mathrm{XIV}$, bacterial), in which they were incubated for $25 \mathrm{~min}$ at $37^{\circ} \mathrm{C}$. The HBSS enzyme solution was supplemented with the following (in $\mathrm{mM}$ ): 1 pyruvic acid, 1 kynurenic acid, $0.1 \mathrm{N \omega}$-nitro-L-arginine, and 0.005 glutathione, $\mathrm{pH} \approx 7.4$ (300 mOsm/1). After enzyme treatment, the neurons were mechanically dissociated by triturating with a series of progressively smaller fire-polished Pasteur pipettes. The dissociation solution was oxygenated and contained the following (in $\mathrm{mM}$ ): 140 sodium isethionate, 2 $\mathrm{KCl}, 4 \mathrm{MgCl}_{2}$, 23 glucose, $15 \mathrm{HEPES}, 1$ kynurenic acid, $0.1 \mathrm{N \omega}$-nitro-Larginine, and 0.005 glutathione, $\mathrm{pH} \approx 7.4(300 \mathrm{mOsm} / 1)$. The tissue suspension was then placed in a $35 \mathrm{~mm}$ Petri dish positioned on the stage of an inverted microscope. As soon as the neurons settled to the bottom of the dish, they were continuously perfused with physiological saline. The saline solution contained the following (in mM): $140 \mathrm{NaCl}, 2 \mathrm{KCl}, 2$ $\mathrm{MgCl}_{2}, 1 \mathrm{CaCl}_{2}, 23$ glucose, and 15 HEPES, $\mathrm{pH} \approx 7.4(300 \mathrm{mOsm} / 1)$.

ScRT-PCR was performed using protocols similar to those described previously (Tkatch et al., 2000). Individual neurons were patched and aspirated into micropipettes while being continuously perfused by the control solution. The micropipettes contained $1 \mu \mathrm{l}$ of diethylpyrocarbonate (DEPC)-treated water and $0.8 \mathrm{U} / \mu \mathrm{l}$ SUPERase-In (Ambion, Austin, TX). To minimize RNase activity, the micropipettes were autoclaved, sterile gloves were worn at all times during the procedures, and the external control solutions were prepared with essentially RNase-free water. After aspirating the cell into the tip of the micropipette, the tip was broken off and the contents were expelled into an Eppendorf tube containing Superase-In $(0.7 \mu \mathrm{l}, 20 \mathrm{U} / \mu \mathrm{l})$ (Ambion), DEPC-treated water $(1.9 \mu \mathrm{l})$, BSA $(0.7 \mu \mathrm{l}, 143 \mu \mathrm{g} / \mu \mathrm{l})$, dNTPs $(1.0 \mu \mathrm{l}, 10 \mathrm{~mm})$, and oligo-dT $(0.7 \mu \mathrm{l}, 0.5 \mu \mathrm{g} / \mathrm{ml})$ (Invitrogen, Gaithersburg, MD).

Single-stranded cDNA was generated by RT. First, the neuroncontaining mixture was heated to $65^{\circ} \mathrm{C}$ for 5 min to denature the nucleic acids and then cooled on ice for $1 \mathrm{~min}$. To this mixture was added $10 \times$ RT buffer $(2 \mu \mathrm{l}), \mathrm{MgCl}_{2}(4 \mu \mathrm{l}, 25 \mathrm{~mm})$, DTT ( $\left.2 \mu \mathrm{l}, 0.1 \mathrm{~m}\right)$, Rnase Out (1 $\mu \mathrm{l}, 40 \mathrm{U} / \mu \mathrm{l}$ ), and DEPC-treated water (Invitrogen) to bring the final volume to $20 \mu$ l. The reaction mixtures were heated at $42^{\circ} \mathrm{C}$ for $2 \mathrm{~min}$, at which point SuperScript II $(0.7 \mu \mathrm{l}, 50 \mathrm{U} / \mu \mathrm{l})$ (Invitrogen) was added. Next, these RT reactions were run at $42^{\circ} \mathrm{C}$ for $50 \mathrm{~min}$. The temperature was then increased to $70^{\circ} \mathrm{C}$ for $15 \mathrm{~min}$ to terminate the reactions. Finally, to eliminate any residual RNA, RNase $\mathrm{H}(0.5 \mu \mathrm{l}, 2 \mathrm{U} / \mu \mathrm{l})$ (Invitrogen) was added, and the reaction mixtures were held at $37^{\circ} \mathrm{C}$ for $20 \mathrm{~min}$.

PCR amplification of the resulting CDNA was done using previously described methods and thermal cycler (P-200; MJ Research, Watertown, $\mathrm{MA})$. The primer sequences for $\mathrm{Ca}^{2+}$ - and calmodulin-dependent kinase type-II (CaMKII) have been published previously (Vysokanov et al., 1998 ) and have a predicted product length of $354 \mathrm{bp}$. In these reactions, a 55 cycle touchdown protocol was implemented for more efficient amplification of single-cell cDNA (Day et al., 2002). In PCRs for both HCN1-HCN4 and Kir2.1-Kir2.4, multiplexed and nested amplification techniques with 20 first-round cycles and 35 second-round cycles were used. The primers for HCN1-HCN4 have been published previously (Franz et al., 2000) and have predicted product lengths of 291, 370, 233, and $169 \mathrm{bp}$, respectively. The primers for Kir2.1-Kir2.4 were as follows: Kir2.1 (GenBank accession number X73052) upper primer GCCCTTTATATGACTTGAGTA (position 1167), lower primer GCTTGCCTGGTTGTGGAG (position 1562), PCR product size of 413; Kir2.2 (GenBank accession number NM010603) upper primer ACCACACAGGCTCGCAGTTCC (position 1441), lower primer AAATCTCCGACTCCCGTCT (position 1780), PCR product size of 358; Kir2.3 (GenBank accession number NM008427) upper primer CACGTGCCCAGGCGGAAAC (position 124), lower primer CCAGAAGAGGAGGCCGAAGAA (position 307), PCR product size of 204; and Kir2.4 (GenBank accession number NM145963) upper primer ACAGCCCTAAGTCAAGTTT (position 1303), lower primer CATCTTTGGGAAGGGGTGTCACA (position 1514), PCR product size of 234. The optimal anneal- ing temperatures for the primers were determined using Oligo software (version 6.4; National Biosciences, Plymouth, MN).

For each set of single-cell reactions, both positive and negative controls were performed. Positive controls were run with pooled PFC cDNA. Negative controls were run in which the cell was omitted from one reaction mixture in each set. In the data presented, both controls yielded appropriate results. Because HCN4 was only detected in 10\% of individual cells and Kir 2.4 was only detected in $7 \%$ of individual cells, we tested both the amplification efficiency of these primer sets and the relative abundance of these mRNAs in two ways. First, we ran a dilution series for each PCR product starting with $1 \mu$ l of RT product, derived from pooled PFC tissue mRNA, and then diluting it 1:10, 1:25, 1:50, 1:100, 1:200, $1: 400$, and 1:1000. HCN4 signal was not detected beyond the 1:10 dilution point, but Kir2.4 was detected at 1:100 dilution. The HCN primer sets were then tested on whole-brain tissue in which HCN4 was detectable at dilutions of 1:1000. This suggests that the performance of the primer was adequate and that HCN4 and Kir2.4 mRNAs were either not expressed or were below our threshold for detection in individual PPNs.

Cell culture. Time pregnant C57BL/6 mice were anesthetized with a mixture of xylazine $(75 \mathrm{mg} / \mathrm{kg})$ and ketamine $(5 \mathrm{mg} / \mathrm{kg})$ on gestational day 17. Embryos were aseptically removed from the uterus, decapitated, and placed in cold HBSS, pH 7.4. Cortical tissue was dissected from each embryo and dissociated by mechanical trituration with a series of increasingly smaller fire-polished Pasteur pipettes in the serum, containing plating medium as described previously (Akins et al., 1990). Dissociated neurons were plated on $12 \mathrm{~mm}$ coverslips coated with polyethylenimine in a 24 -well plate at a density of $7.5 \times 10^{4} / \mathrm{cm}^{2}$. Cultures were maintained in a humid, $5 \% \mathrm{CO}_{2}$ atmosphere at $37^{\circ}$. After $24 \mathrm{~h}$, three-quarters of the medium was replaced with a Neurobasal medium (Invitrogen, Grand Island, NY) supplemented with $0.5 \mathrm{~mm}$ L-glutamic acid, $1 \times \mathrm{B} 27$, and $50 \mathrm{mg} / \mathrm{l}$ penicillin/streptomycin. At 4 days in vitro (DIV), $5 \mu \mathrm{M}$ cytosine arabinoside (AraC) (Sigma) was added to the culture to control non-neuronal proliferation.

Immunocytochemistry. At $7 \mathrm{DIV}$, cortical cultures grown on glass coverslips were fixed with $4 \%$ freshly depolymerized paraformaldehyde for $0.5 \mathrm{~h}$ at $4^{\circ} \mathrm{C}$. Cultures were then blocked in $5 \%$ normal goat serum containing $0.05 \%$ Triton X-100 and subsequently incubated overnight at $4^{\circ} \mathrm{C}$ with the following antibodies: mouse anti- microtubule-associated protein (MAP2) (1:250; kindly provided by Prof. Lester I. Binder, Northwestern University, Chicago, IL); rabbit anti-Kir2.2 (1:50 to 1:100; Sigma), and rabbit anti-Kir2.3 (1:50 to 1:100; Sigma). After rinsing in PBS, the appropriate species-specific secondary antibodies coupled to fluorescein and rhodamine fluorophores (Alexa Fluor 488 and 568 IgG; Molecular Probes, Eugene, OR) were applied. Cultures were mounted with Vectashield (Vector Laboratories) and viewed under a Nikon (Tokyo, Japan) Eclipse 800 microscope. Cultures incubated without the appropriate primary or secondary antibody lacked immunoreaction signal. Double-label immunofluorescence controls included dual-channel recordings of single-labeled cultures to exclude possible bleeding-through of the detected signals. Specificity of the affinity-purified Kir2.2 and Kir2.3 antibodies also was checked by examining sections of rat brain to determine whether the staining pattern matched that found using mRNA localization techniques (Falk et al., 1995; Horio et al., 1996); these experiments revealed a consistent match between antibody staining and mRNA distributions. The distribution pattern was also similar to that of a recent report using a different set of antibodies (Pruss et al., 2005). All images were processed with Adobe Photoshop CS (Adobe Systems, San Jose, CA) to adjust contrast and brightness.

\section{Results}

HCN currents in PrL/IL pyramidal neurons activate rapidly

Layer V-VI PPNs were visually identified using infrared optics (Franklin and Paxinos, 1997). Whole-cell recordings were made with biocytin-filled electrodes for postrecording identification (Fig. 1A). Recorded neurons had morphological features typical of tufted pyramidal neurons (Markram et al., 1997); that is, in addition to basal dendrites, these neurons had a long apical dendrite extending to the superficial cortical layers, in which it 

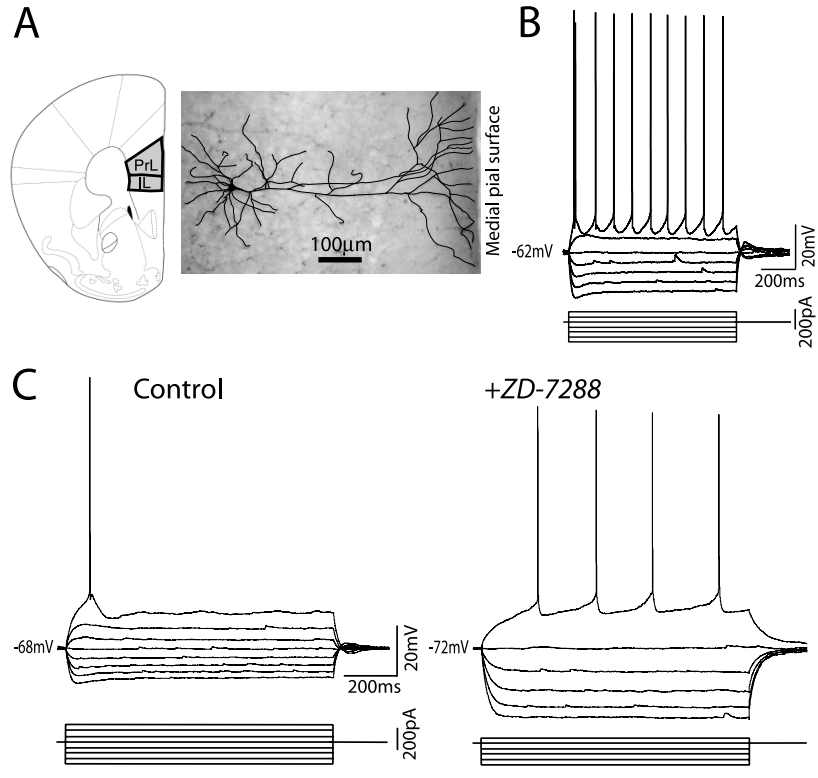

Figure 1. Pyramidal neurons in mouse PrL/LL cortex have fast hyperpolarization-induced voltage sag. $A$, Left, A slice of mouse brain containing PrL/L cortex (adapted from Franklin and Paxinos, 1997). Right, Biocytin-filled deep-layer (V-VI) PPN from the outlined area in $\boldsymbol{A}$. The PPN was approximately reconstructed for clearer visualization of the fine dendritic processes that can be seen extending to the medial pial surface of the slice. $\boldsymbol{B}$, Whole-cell current-clamp recording from the PPN in $\boldsymbol{B}$ showing classic initial doublet followed by steady firing during depolarization current injection and fast sag initiated by hyperpolarizing current injection. $\boldsymbol{C}$, Left, Control current-clamp recording from a PPN at rest with current steps from -200 to +200 pA. In the control condition, the cell fired spikes at $150-200 \mathrm{pA}$ of current injection. Right, Same cell $>10$ min after application of $50 \mu \mathrm{m}$ ZD-7288. The cell hyperpolarized $4 \mathrm{mV}$ while firing spikes with less current injection $(50-100 \mathrm{pA})$, and the voltage sag was abolished.

branched extensively. With our recording solutions, the resting membrane potential of these neurons was typically approximately $-65 \mathrm{mV}$, and they rarely spiked. Injection of negative current steps $(-200$ to $-50 \mathrm{pA})$ produced a rapid hyperpolarization, followed by a depolarizing sag. This response pattern is typical of neurons expressing $\mathrm{HCN}$ channel currents in other tissues (Maccaferri et al., 1993; Magee, 1998; Berger et al., 2001) (Fig. $1 B$ ). The amplitude of the voltage sag increased with more negative somatic current injection. This pattern of response was similar in all of the pyramidal neurons studied, regardless of whether they responded to depolarizing current injection with a two-spike burst (as in Fig. 1) or not.

To verify that the depolarizing sag was attributable to $\mathrm{HCN}$ channel currents, the protocol was repeated in the presence of the HCN channel antagonist ZD-7288 (Harris and Constanti, 1995). The application of ZD-7288 at nominally saturating concentrations $(50 \mu \mathrm{M})$ for at least $10 \mathrm{~min}$ had two clear effects on PPN physiology. First, as in hippocampal neurons, HCN channel block resulted in a modest, but consistent, hyperpolarization of the somatic membrane $(-5 \pm 3 \mathrm{mV} ; n=15)$. Second, ZD-7288 abolished the sag in membrane voltage after hyperpolarizing current steps (Fig. 1C). The loss of the HCN conductance at hyperpolarized membrane potentials led to a significant increase in the slope resistance at $-80 \mathrm{mV}$; the median resistance was $55 \mathrm{M} \Omega$ before HCN channel block and $244 \mathrm{M} \Omega$ after block $(n=8 ; p<$ 0.01, Wilcoxon's matched-pairs test; data not shown).
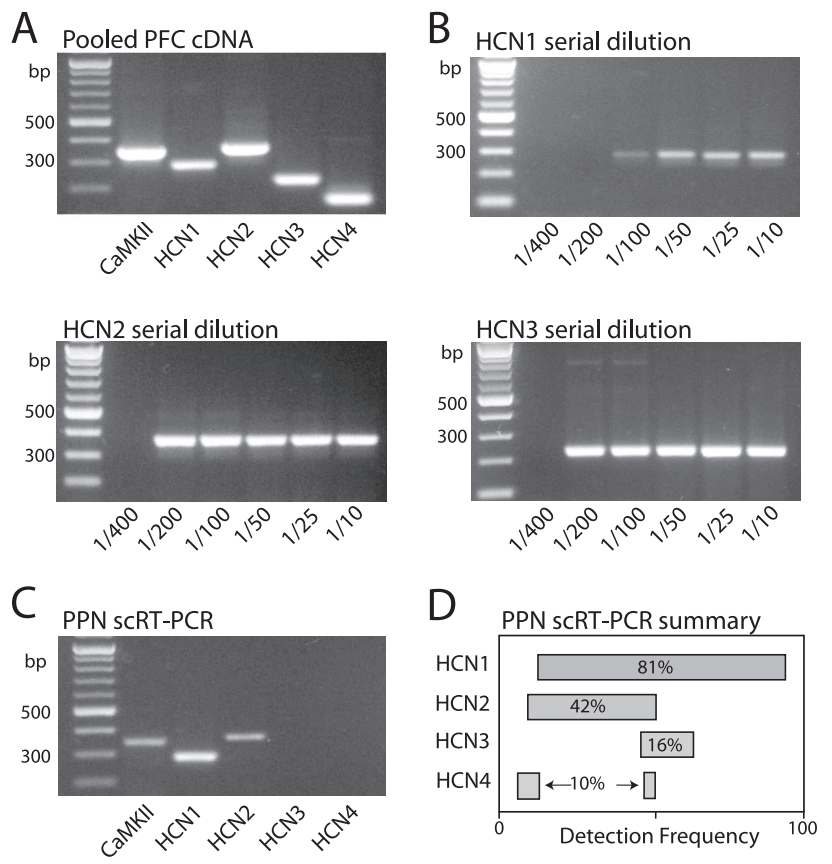

Figure 2. PrL/IL pyramidal neurons primarily express HCN1 and HCN2 mRNAs. $\boldsymbol{A}$, Positive control for sCRT-PCR experiments showing that mRNAs from HCN1-HCN4 and CaMKII were all expressed within the PrL/IL cortex. $\boldsymbol{B}$, A set of serial dilution experiments from pooled PrL/IL tissue showed that HCN1-HCN4 mRNA transcripts are expressed in cells in this brain region. HCN2 and HCN3 showed the most robust expression, followed by HCN1 (HCN4 showed the weakest expression with signal loss after 1:10 dilution and is therefore not shown). C, Individual cell representative of $\sim 40 \%$ of single cells profiled showing pronounced HCN1 mRNA expression with weak HCN2 expression. $\boldsymbol{D}$, Graph of the detection frequency of HCN1-HCN4 mRNA transcripts in 31 individual CaMKII-positive cells profiled.

\section{PPNs neurons coexpress HCN channel mRNAs}

Four HCN channel subunits have been cloned that contribute to brain HCN channels: HCN1, HCN2, HCN3, and HCN4 (Clapham, 1998). Subunit composition determines HCN channel gating kinetics and susceptibility to regulation by cAMP (Santoro et al., 2000). Pyramidal neurons from the CA1 hippocampal subfield and from the somatosensory cortex coexpress all four subunit mRNAs, whereas dopaminergic and thalamic relay neurons coexpress HCN2-HCN4 mRNAs but do not have detectable levels of HCN1 (Franz et al., 2000; Notomi and Shigemoto, 2004). In these two groups of neurons, HCN1 expression is correlated with rapid $\mathrm{HCN}$ channel activation like that seen in PPNs.

As a first step toward determining whether a similar correlation was present in PFC, RT-PCR experiments were performed at the tissue level. RT-PCR profiling of pooled PrL/IL cortex cDNA confirmed that all four $\mathrm{HCN}$ transcripts were expressed at detectable levels (Fig. 2A). Next, to generate an estimate of relative transcript abundance, serial dilution experiments were performed (Fig. 2B). These assays suggested that HCN1-HCN3 mRNAs were relatively abundant, being detectable with cDNA dilutions of 100:1 or greater. Conversely, HCN4 mRNA was detectable only at dilutions of 10:1 or less (data not shown). Because the PrL/IL cortex is heterogeneous, individual deep-layer PPNs were profiled for expression of HCN1-HCN4 mRNAs. Neurons were screened for CaMKII mRNA to verify their identification as pyramidal neurons (Benson et al., 1992). The vast majority $(>80 \%)$ of the PPNs examined had detectable levels of HCN1 mRNA $(n=31)$ (Fig. $2 C, D)$. However, more than half of this population also had detectable levels of HCN2 or HCN3 
mRNA, with HCN2 being the most commonly detected $(42 \%)$ of the two. HCN4 was detected in only a small subset of the PPNs profiled (10\%) (Fig. 2D).

\section{PPN HCN channel currents are rapidly activating}

These data show that PPNs have the capacity to form homomultimeric or heteromultimeric channels composed primarily of HCN1 and HCN2 subunits (Chen et al., 2001; Xue et al., 2002; Ulens and Siegelbaum, 2003). To gain a better picture of the kinetic features of the channels expressed by PPNs, somatic voltageclamp experiments were performed. In these experiments, the soma was held at $-50 \mathrm{mV}$ and then stepped to progressively more hyperpolarized potentials in $10 \mathrm{mV}$ increments (Fig. 3A). TTX $(1 \mu \mathrm{M})$ and $\mathrm{Ba}^{2+}(200 \mu \mathrm{M})$ were bath applied to block $\mathrm{Na}^{+}$, Kir, and $\mathrm{K}^{+}$-selective leak channels, thereby preventing spike generation, increasing membrane resistance, and improving voltage control of dendritic regions. To block HCN channels, ZD-7288 $(50 \mu \mathrm{M})$ was applied. Subtraction of control records from those obtained after ZD7288 application allowed isolation of HCN channel currents (Fig. 3B). The $\mathrm{HCN}$ activation relationship was estimated from tail currents generated by a step to $-120 \mathrm{mV}$ (Fig. 3B). Normalized tail current amplitudes were plotted as a function of voltage and then fit with a first-order Boltzmann function. The median half-activation voltage of these fits was $-86 \mathrm{mV}(n=8)$, a value very close to that seen in similar somatic recordings from CA1 pyramidal neurons (Magee, 1998). As can be seen by visual inspection of the traces, HCN channel activation rates were voltage dependent. Singleexponential fits to HCN channel currents are shown as overlays in Figure 3C. Tail currents evoked by stepping from $-120 \mathrm{mV}$ to various other membrane potentials also were reasonably well fit with monoexponential functions (Fig. 3C). Activation and deactivation time constants were averaged and plotted $(n=5)$ (Fig. $3 D$ ). The data were fit with a function constructed from the assumption that there was a single voltage-dependent transition between open and closed states of the channel (see Materials and Methods and below).

The problem with these measurements (and others of their kind) is that they are derived from a somatic "point clamp." That is, the somatic membrane potential is effectively controlled but the dendritic membrane potential, in which the HCN channels are found, is not controlled. One way to overcome this limitation is to make cell-attached patch recordings from dendritic regions (Stuart and Spruston, 1998). However, unlike pyramidal neurons in the hippocampus or in somatosensory cortex, the apical dendrite of PFC pyramidal neurons is of significantly smaller caliber and not restricted to a single plane, making this strategy difficult. As an alternative, computational approaches were used to ap-

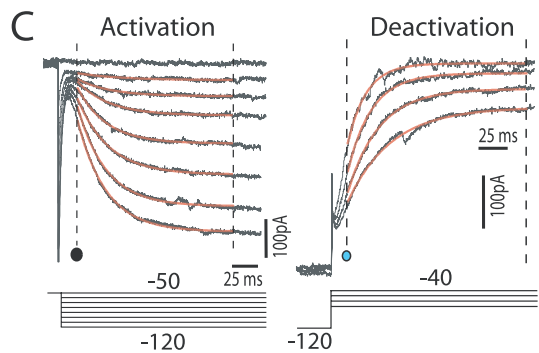

D

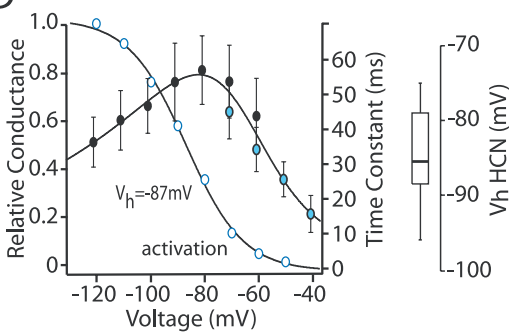

F simulation

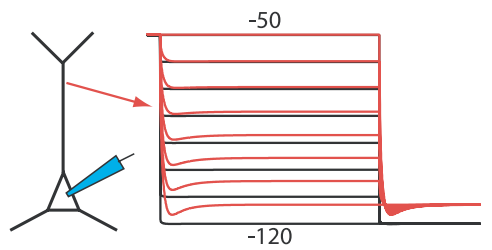

Figure 3. HCN channels rapidly activate at hyperpolarized membrane potentials. $A$, Total current activated by $500 \mathrm{~ms}$ hyperpolarizing voltage steps from -50 to $-120 \mathrm{mV}$ in $10 \mathrm{mV}$ increments. Each step was followed by a $250 \mathrm{~ms}$ step to $-120 \mathrm{mV}$ to ( ated by activation of HCN channels were well fit between the dashed lines with a monoexponential equation (red line); channels were activated by holding the cell at $-50 \mathrm{mV}$ and stepping to $-120 \mathrm{mV}$ at $10 \mathrm{mV}$ increments. Right, Deactivation of HCN channels generated currents that were also fit with a monoexponential function; the membrane potential was held at $-120 \mathrm{mV}$ ( $500 \mathrm{~ms}$ ) 政 potential ( $n=5$ ). For graphical presentation, the resulting plot was then itself fit with equal weight being given to the overlapa Bults in $B$ assuming that the $\mathrm{HCN}$ channel density increased by a factor of 10 from the soma to the first branch point of the apica dendrite or to the end of the basal dendrites. $\boldsymbol{F}$, Plot of the steady-state activation voltage dependence and HCN channel gating kinetics as seen from the soma (black) compared with the actual properties of the dendritic channels (red).

proximate the impact of poor space clamp on the measurements of channel voltage dependence and gating. The simulation program Neuron (Hines and Carnevale, 2001) was used to determine whether the experimental measurements could be reproduced using an anatomically simplified model and dendritically placed HCN channels. HCN channel density was assumed to increase by a factor of 10 from the soma to the ends of the apical and basal dendrites (Magee, 1998; Berger et al., 2001). A simple two-state model of channel gating was used that assumed low levels of cAMP (Wang et al., 2002). With these constraints, the experimental measurements could be reproduced (Fig. 3E). However, as expected from previous studies (Rall et al., 1992), the dendritic voltage in these simulations deviated significantly from the somatic voltage, particularly for more hyperpolarized command voltages (Fig. $3 F$ ). This deviation worsened with higher channel densities. This suggests that the maximal HCN conductance will be underestimated by somatic measurements. Furthermore, because of the limited control at more hyperpolarized membrane potentials, the steady-state voltage dependence should appear to be less steep and channel gating rates slower in this voltage region 

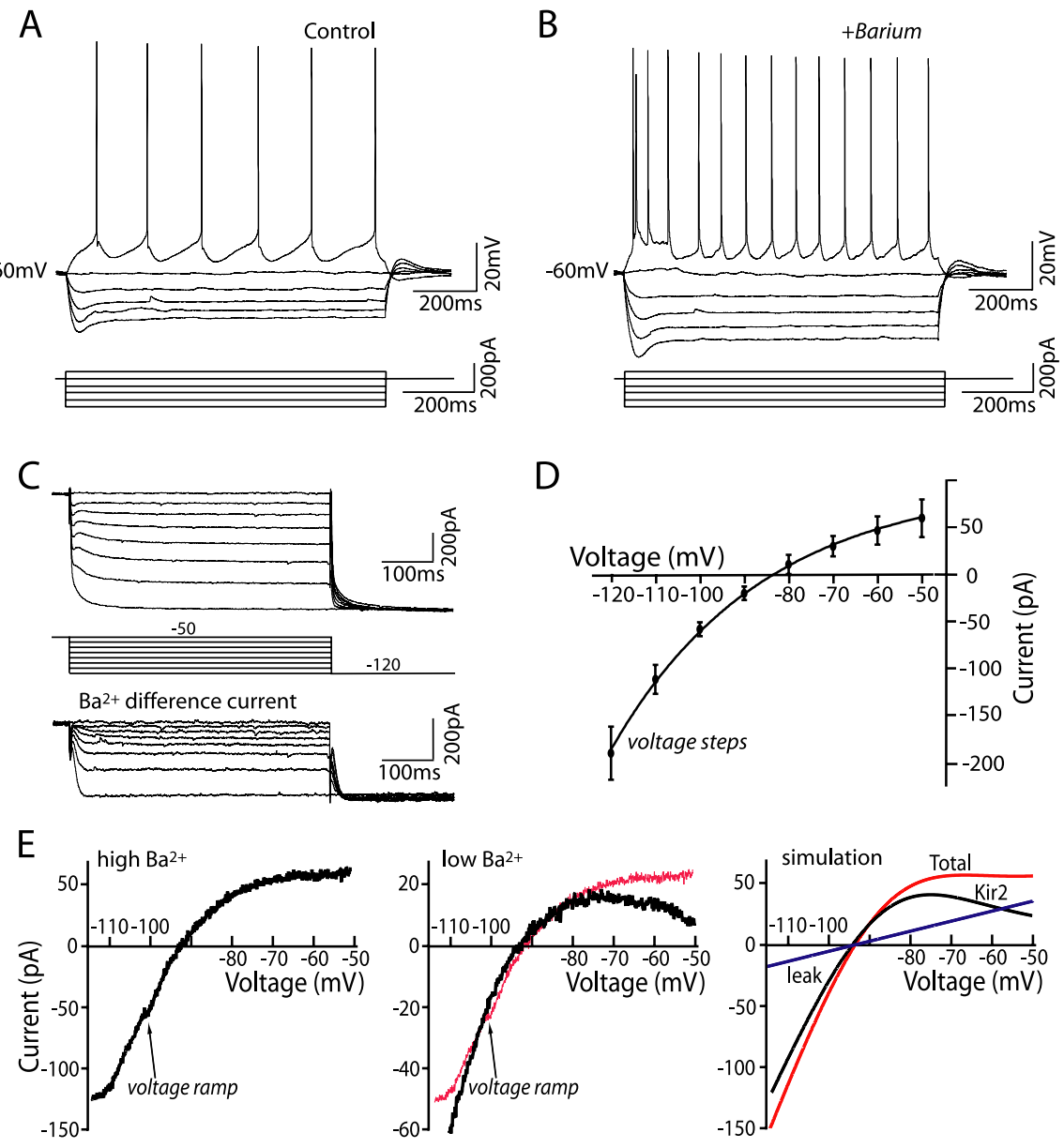

Figure 4. PPNs express $\mathrm{Ba}^{2+}$-sensitive, inwardly rectifying $\mathrm{K}^{+}$channels and linear $\mathrm{K}_{\text {leak }}$ channels. $A$, Whole-cell currentclamp records from a cell at rest during a series of hyperpolarizing and depolarizing steps from -200 to $50 \mathrm{pA}$. $\boldsymbol{B}$, Same cell and step protocol after $\mathrm{Ba}^{2+}(200 \mu \mathrm{M})$ application. During $\mathrm{Ba}^{2+}$ treatment, a negative current had to be injected to repolarize the cell back to the control resting membrane potential that was below the threshold for generating action potentials. These traces show an apparent increase in membrane resistance while the voltage sag remains intact. C, Somatic voltage-clamp analysis of the current-voltage relationship of Kir2 currents. Top, Total current activated by 500 ms hyperpolarizing voltage steps from -50 to $-120 \mathrm{mV}$ in $10 \mathrm{mV}$ increments in the presence of TTX $(1 \mu \mathrm{M})$. Bottom, The $\mathrm{Ba}^{2+}$-sensitive current isolated by subtraction. $\boldsymbol{D}$, Graph showing peak Kir2 current plotted against the step potential generated from averaged data ( \pm SEM; $n=5$ ). $\boldsymbol{E}$, Left, $\mathrm{Ba}^{2+}$-sensitive $(200 \mu \mathrm{m})$ current trace generated from a $100 \mathrm{~ms}$ ramp from -120 to $-50 \mathrm{mV}$ in the presence of TTX and ZD-7288 (black trace). Middle, The black trace shows the current sensitive to lower Ba ${ }^{2+}(50 \mu \mathrm{M})$ superimposed over the $200 \mu \mathrm{m} \mathrm{Ba}{ }^{2+}$ trace (red). Right, Simulated ramp currents derived from the Kir2 channel (black), $K_{\text {leak }}$ channel (blue), and the sum (red) are superimposed.

than they actually are. These observations strengthen the conclusion that the $\mathrm{HCN}$ channels in pyramidal neurons are primarily composed of rapidly gating $\mathrm{HCN} 1$ or $\mathrm{HCN} 1 / \mathrm{HCN} 2$ subunits rather than more slowly gating $\mathrm{HCN} 2$ or $\mathrm{HCN} 3$ subunits (Chen et al., 2001).

\section{Rapidly gating Kir $2 / \mathrm{K}_{\text {leak }}$ channels complement PPN HCN channels}

In addition to the time-varying sag in membrane potential, hyperpolarizing current steps evoked a rapidly gating current that decreased the apparent input resistance of PPNs (Fig. 4A). The application of $\mathrm{Ba}^{2+}(200 \mu \mathrm{M})$ reduced this conductance (Fig. $4 B)$, implicating the constitutively active, inwardly rectifying Kir2 channels (Coetzee et al., 1999). $\mathrm{Ba}^{2+}$ not only reduced currents evoked by hyperpolarizing current steps but also depolarized neurons $(\sim 10-15 \mathrm{mV})$ and increased spiking evoked by depolarizing current injection. Somatic voltage-clamp experiments revealed that PPNs expressed an inwardly rectifying, $\mathrm{K}^{+}$selective conductance with properties similar to those described for Kir2 channels. As described above, in the presence of TTX, hyperpolarizing voltage steps evoked currents with both rapid and slow kinetics (Fig. 4C). The application of $\mathrm{Ba}^{2+}(200$ $\mu \mathrm{M})$ selectively reduced the rapidly gating component of the current (in contrast to the effects of ZD-7288) (Fig. 4C). The selectivity of the block is seen best in the difference currents generated by subtraction of currents evoked in the absence and presence of $\mathrm{Ba}^{2+}$ (Fig. 4C). Plots of the current amplitude as a function of step voltage show that the current rectified and that it reversed near the $\mathrm{K}^{+}$equilibrium potential $(n=6)$ (Fig. $4 D)$. Because the current is non-inactivating, fast voltage ramps from depolarized holding potentials were also used to estimate the current-voltage relationship. In the presence of TTX and ZD-7288, a voltage ramp from -120 to $-50 \mathrm{mV}(100 \mathrm{~ms})$ evoked a $\mathrm{Ba}^{2+}$-sensitive current that rectified and reversed near the $\mathrm{K}^{+}$equilibrium potential (Fig. $4 E$, left). Although both step and ramp protocols suggested that the channels underlying this current rectified, they did not strongly rectify and appeared to carry a substantial outward current between the resting membrane potential and spike threshold, consistent with the ability of $\mathrm{Ba}^{2+}$ to push PPNs to sustained spiking.

Kir2 channels are likely to be responsible for much of the $\mathrm{Ba}^{2+}$-sensitive currents seen in PPNs. However, are they responsible for all of it? In heterologous systems, Kir2 channels are strongly rectifying as the channels become blocked at potentials above the $\mathrm{K}^{+}$equilibrium potential (Coetzee et al., 1999). This suggests that $\mathrm{Ba}^{2+}$ might be blocking another $\mathrm{K}^{+}$ channel in addition to Kir2 channels. Using lower concentrations of $\mathrm{Ba}^{2+}(50 \mu \mathrm{M})$, a difference current with greater rectification, closer to that expected for Kir2 channels, was found (Fig. $4 E$, middle); this finding supports the idea that there were at least two $\mathrm{K}^{+}$channels blocked by the higher $\mathrm{Ba}^{2+}$ concentration. Neuron simulations with an anatomically reduced model (as above) were able to accurately reproduce the somatic voltage ramp data using a strongly rectifying Kir2 channel and a linear, $\mathrm{K}^{+}$-selective leak channel $\left(\mathrm{K}_{\text {leak }}\right)$ that was present at lower density (Fig. 3E, right). These simulations assumed that the $\mathrm{K}^{+}$channels were uniformly distributed in the somatodendritic membrane (see below), but the outcome was not strongly dependent on this assumption. Additional support for this deconstruction of the $\mathrm{Ba}^{2+}$-sensitive current into two components came from the ability to reliably detect both KCNK3 and KCNK9 mRNA in PPNs ( $n=8$; data not shown); these subunits form $\mathrm{K}^{+}$-selective, "leak" channels with a lower $\mathrm{Ba}^{2+}$ affinity than Kir2 channels (Goldstein et al., 2001).

These $\mathrm{K}^{+}$channels play an important role in determining the "resting" membrane potential of PPNs. The application of $\mathrm{Ba}^{2+}$ 


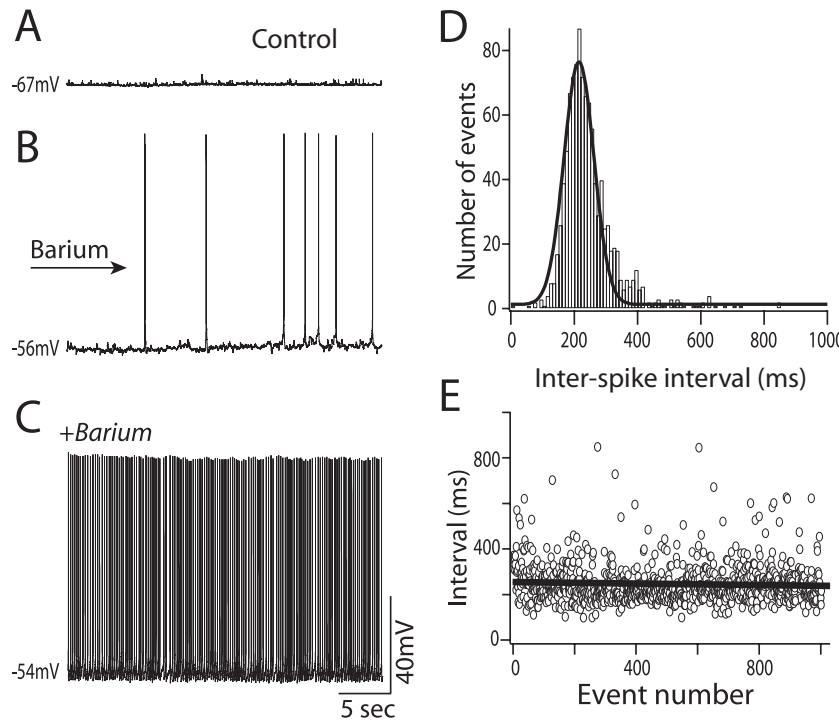

Figure 5. Standing Kir2 and $K_{\text {leak }}$ currents determine the resting membrane potential in PPNs. $\boldsymbol{A}$, Control trace from PPN quiescent at rest in standard ACSF. $\boldsymbol{B}$, After Ba $^{2+}(200 \mu \mathrm{m})$ application, the cell depolarizes and begins to fire action potentials. $\boldsymbol{C}$, The firing frequency stabilizes within 5-10 min after initiation of $\mathrm{Ba}^{2+}$ superfusion. $\boldsymbol{D}$, Histogram of the interspike interval from C plotted against number of spikes (events) has a Gaussian distribution with a mode of $215 \pm 1 \mathrm{~ms}$. $\boldsymbol{E}$, A plot of the interspike interval in order of occurrence shows that the stability in firing frequency persists over time. The data were fit with linear regression (black line) and had a slope of -0.01 and $y$-intercept at $250 \mathrm{~ms}$.

$(200 \mu \mathrm{M})$ to block Kir2 and $\mathrm{K}_{\text {leak }}$ channels led to a progressive depolarization and spike generation (Fig. $5 A, B$ ). After a few minutes in $\mathrm{Ba}^{2+}$, PPNs reached a steady-state discharge rate (Fig. $5 C)$. Typically, this low-frequency $(4-5 \mathrm{~Hz})$, regular spiking was remarkably stable, continuing for $1 \mathrm{~h}$ or more $(n=6)$. Hyperpolarization readily stopped spiking, which resumed after cessation of the current injection (data not shown). Interval analysis of the spiking typically yielded Gaussian distributions, as for the neuron shown in Figure $5 A-D$ (mode, $215 \mathrm{~ms}$ ). The stability of the response is evident in plots of spike (event) number against the interspike interval (Fig. $5 E$ ). The data were fit by linear regression that had a negligible slope $(-0.01)$ and a $y$-intercept of $250 \mathrm{~ms}$ or $4 \mathrm{~Hz}$. All of the cells analyzed in this way were similar (median discharge rate, $4.5 \mathrm{~Hz} ; n=4$ ).

\section{Inwardly rectifying $\mathrm{K}^{+}$currents are attributable to Kir2.2/Kir2.3 channels}

As discussed above, the biophysical and pharmacological properties of the rapidly activating currents are consistent with their attribution in large part to Kir2 channels (Coetzee et al., 1999). Previous work has shown that Kir2 channel genes are expressed in neocortex (Karschin et al., 1996), but their expression in deeplayer PrL/IL cortex has not been described. Therefore, PrL/IL cortex tissue and individual PPNs were profiled for expression of all four Kir2 genes known to be expressed in brain (Kir2.1, Kir2.2, Kir2.3, and Kir2.4). Serial dilution RT-PCR analysis of PrL/IL cortex tissue revealed a robust expression of Kir2.1 (Fig. 6A), Kir2.2 (Fig. 6B), and Kir2.3 (Fig. 6C), whereas Kir2.4 appeared to be expressed at lower levels (Fig. 6D). At the single-cell level, Kir2.3 was detectable in all identified PPNs $(n=15)$ (Fig. $6 E, F)$; $>60 \%$ these neurons also had detectable levels of Kir2.2 mRNA, and $43 \%$ had detectable expression of Kir2.1. Conversely, Kir2.4 mRNA was rarely seen in PPNs. These results suggest that the $\mathrm{K}^{+}$-selective, inwardly rectifying, $\mathrm{Ba}^{2+}$-sensitive currents in
A

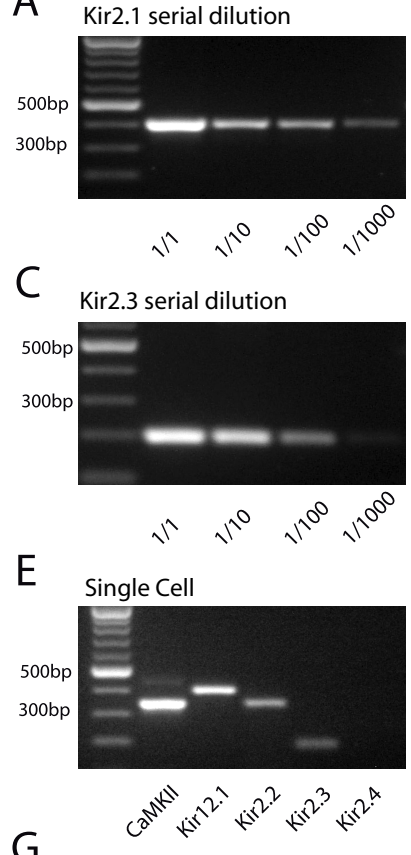

B

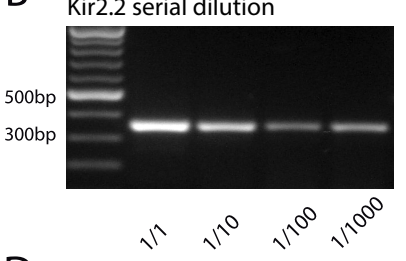

D

Kir2.4 serial dilution

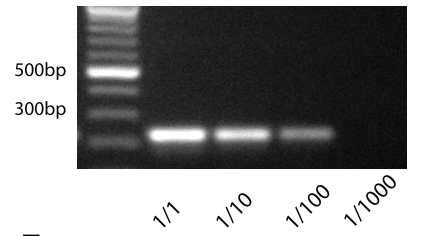

$\mathrm{F}$
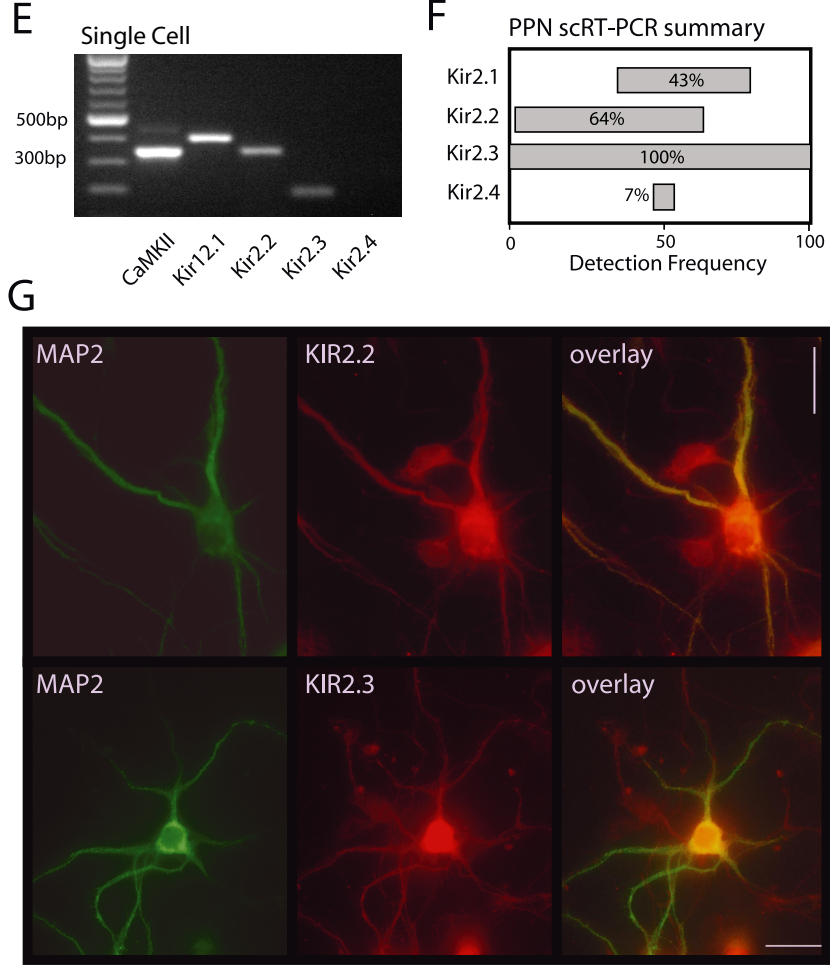

Figure 6. Inwardly rectifying $\mathrm{K}^{+}$channels in PPNs are attributable to Kir2.2, and Kir2.3 subunits that are present in the dendrites. Serial dilution experiments from pooled PrL/LL tissue showed that Kir2.1 (A), Kir2.2 (B), Kir2.3 (C), and Kir2.4 (D) subunit mRNAs are all expressed in this region. $\boldsymbol{E}$, Individual cell representative of $30 \%$ of single cells profiled showing clear Kir2.1, Kir2.2, and Kir2.3 mRNA expression. Kir2.4 was rarely detected in individual cells. $F$, Graph of the detection frequency of Kir2 mRNA transcripts in 15 individual CaMKII-positive PrI//L cells profiled shows consistent detection of Kir2.3 (100\%) and Kir2.2 (64\%), less detection of Kir2.1 (30\%), and very little detection of Kir2.4 (7\%). G, Immunocytochemistry shows dendritic colocalization of MAP2 with Kir2.2 protein (top row) and Kir2.3 protein (bottom row) in cultured cortical neurons. Scale bars, $30 \mu \mathrm{m}$.

PPNs are attributable to channels containing Kir2.3, Kir2.2, and, to some extent, Kir2.1 subunits.

To determine the subcellular localization of Kir2 channel proteins, immunocytochemical approaches were used. In tissue slices from adult brain, neuropil staining for Kir2.2 and Kir2.3 subunits was strong, making identification of individual dendrites difficult. As a consequence, cortical neurons were cultured at low density for study. MAP2 was used as a marker of neuronal dendrites (Fig. 6G). Both Kir2.2 (Fig. 6G, top) and Kir2.3 (Fig. 

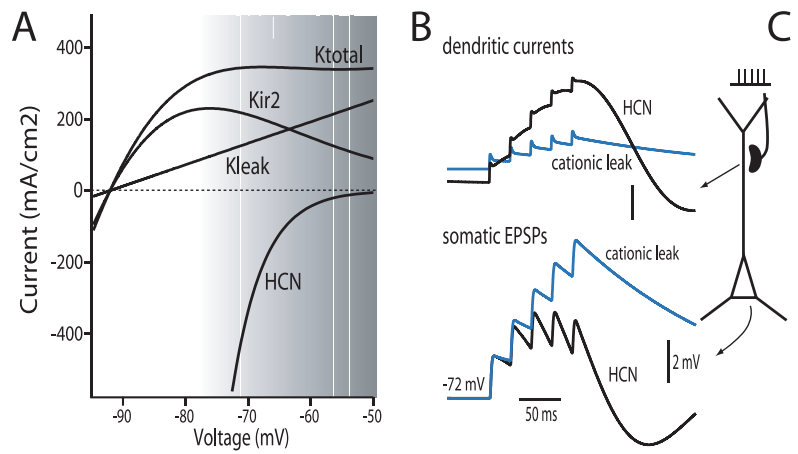

C

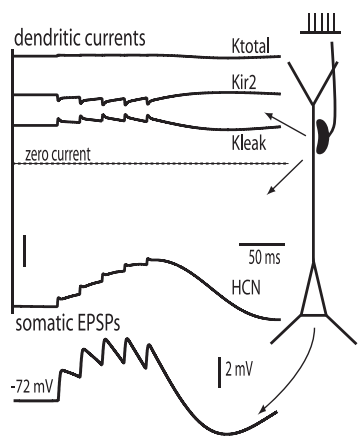

Figure 7. Neuron simulations suggesting that Kir2 and $\mathrm{K}_{\text {leak }}$ channels are necessary for $\mathrm{HCN}$-mediated sublinear summation of dendritic EPSPs. $\boldsymbol{A}$, Current-voltage relationships for Kir2, $\mathrm{K}_{\text {leak }}$, and HCN channels derived from voltage-clamp experiments. The sum of Kir2 and $K_{\text {leak }}$ currents is shown as Ktotal. $B$, Dendritic HCN current density at the site of an excitatory synaptic input, positioned $75 \%$ of the way to the first branch point of the apical dendrite. At the bottom, the somatic EPSP resulting from the dendritic input is shown. Note the sublinear summation. Replacing the HCN channels with ohmic cation leak channels at a density that maintains the resting membrane potential results in more linear summation of EPSPs. Vertical scale bar, $50 \mathrm{~mA} / \mathrm{cm}^{2}$.C, Top, Plot showing Kir2, $\mathrm{K}_{\text {leak }}$ and $\mathrm{HCN}$ current densities at the dendritic site of synaptic contact. Bottom, The somatic EPSP displaying prominent sublinear summation. Note that Kir2 currents are reduced and $\mathrm{K}_{\text {leak }}$ currents are increased during the EPSP, resulting in little net change in outward current attributable to these $\mathrm{K}^{+}$channels. $\mathrm{HCN}$ channels deactivate, producing a net outward change in current during the EPSP train. Vertical scale bar, $100 \mathrm{~mA} / \mathrm{cm}^{2}$.

$6 G$, bottom) labeling was prominent in both soma and dendrites. These data support the inference that Kir2 channels are found in dendrites and are coextensive with HCN channels.

\section{Simulation of the interaction among $\mathrm{HCN}$, Kir2, and $\mathrm{K}_{\text {leak }}$ channels in dendritic regions}

To help understand the potential role of $\mathrm{HCN}$, Kir2, and $\mathrm{K}_{\text {leak }}$ channels in regulating dendritic synaptic integration, simulations were performed using the channel descriptions inferred from the somatic voltage-clamp experiments in an anatomically simplified PPN. Kir2 and $K_{\text {leak }}$ channel densities were as determined by fitting the experimental data. Because the previous simulations suggested that the HCN channel density was underestimated, it was increased to produce a resting membrane potential near -70 $\mathrm{mV}$ when Kir2 and $\mathrm{K}_{\text {leak }}$ channels were present, as found experimentally. The current-voltage relationship of HCN, Kir2, and $\mathrm{K}_{\text {leak }}$ channels at their estimated densities is shown in Figure $7 \mathrm{~A}$.

The impact of HCN channels on summation of dendritic EPSPs was determined using a $40 \mathrm{~Hz}$ train of EPSPs delivered threequarters of the way up the apical dendrite. These EPSPs effectively deactivated HCN channels, creating an outward hyperpolarizing current that led to sublinear summation (Fig. $7 B$ ). This sublinearity was quantified by computing the ratio of the last to the first EPSP in the train. In the control condition, this ratio was less than two (Fig. 8D). Replacing HCN channels with cationic leak channels, to maintain the resting membrane potential near $-70 \mathrm{mV}$, led to greater additivity of EPSPs (EPSP5/EPSP1 of 3.7), emphasizing the importance of channel deactivation in bringing about the sublinearity (Fig. 7B). These results suggest that PPN HCN channels function in much the same way as those found in hippocampal pyramidal neurons and promote sublinear EPSP summation (Magee and Carruth, 1999).

The functional role of the Kir2 and $\mathrm{K}_{\text {leak }}$ channels was examined using a similar strategy. Kir 2 and $\mathrm{K}_{\text {leak }}$ channels generated a large standing outward current that helped maintain the membrane potential near $-70 \mathrm{mV}$ (Fig. $7 \mathrm{~A}$ ). At this membrane potential, there was significant $\mathrm{HCN}$ activation, creating a dynamic interaction between depolarizing and hyperpolarizing ionic forces. As shown in Figure 7C, a train of EPSPs (40 Hz) summed sublinearly at this potential attributable to HCN channel deacti- vation. Interestingly, Kir2 channels provided a modest inward, depolarizing current because of channel rectification that was balanced by that from $\mathrm{K}_{\text {leak }}$ channels, resulting in no net change in current during the EPSP train (Fig. 7C, Ktotal).

Despite the fact that the aggregate $\mathrm{K}^{+}$ channel current did not directly shape the EPSP waveform, it did play an important role by keeping the $\mathrm{HCN}$ channels active and in a steep region of their current-voltage relationship. This is best illustrated by simulations in which the $\mathrm{K}^{+}$channel densities were reduced and the effects on EPSP summation examined. Reducing total $\mathrm{K}^{+}$ channel density by $50 \%$ caused the membrane to depolarize and HCN channels to deactivate (Fig. $8 \mathrm{~A}$ ). At this membrane potential, the EPSP train produced less $\mathrm{HCN}$ channel deactivation and less net outward current, leading to greater EPSP summation (EPSP5/EPSP1 of $\sim 3$ ) (Fig. 8A,D). Subsequent reduction in $\mathrm{HCN}$ channel density by $50 \%$ (mimicking block) led to membrane hyperpolarization but little change in EPSP summation (Fig. $8 \mathrm{~A}$ ). Alignment of the voltage traces before delivery of the EPSP train in the three conditions illustrates this point (Fig. $8 \mathrm{~A}$, bottom).

To contrast the roles of Kir 2 and $K_{\text {leak }}$ channels in this process, simulations were run with dendrites that contained only one channel or the other. The density of the channels was adjusted to keep the resting membrane potential near $-70 \mathrm{mV}$. With only $\mathrm{K}_{\text {leak }}$ channels, the sublinearity of summation was more pronounced as the outward currents generated by the $K_{\text {leak }}$ channels summed with those produced by deactivation of HCN channels (EPSP5/EPSP1 of $\sim 1$ ) (Fig. $8 B, D$ ). Reducing $\mathrm{K}_{\text {leak }}$ by $50 \%$ increased summation (EPSP5/EPSP1 of $\sim 2$ ) but by much less than seen with the admixture of Kir2 channels. In contrast, replacing $\mathrm{K}_{\text {leak }}$ channels with Kir2 channels increased EPSP summation (Fig. 8C), elevating the EPSP5/EPSP1 ratio to near 3. This was attributable to the generation of net inward current as Kir2 channels blocked with depolarization, counteracting the net outward current generated by deactivation of HCN channels. Reducing Kir2 density by $50 \%$ led to greater membrane depolarization than reducing $\mathrm{K}_{\text {leak }}$ channel density by $50 \%$ (because of the negative slope conductance at this membrane potential). This difference led to an additional increase in EPSP summation (Fig. 8C, bottom, $D)$.

\section{Blocking Kir $2 / \mathrm{K}_{\text {leak }}$ channels increases summation of EPSPs evoked by superficial layer stimulation}

Although these simulations were helpful in thinking about the roles of Kir2 and $\mathrm{K}_{\text {leak }}$ channels in shaping dendritic integration, they are based on a very simple model and may not accurately reflect what actually happens in PPNs. To test these predictions, whole-cell recordings were made from layer V PPNs and the superficial layers (I/II) stimulated to evoke EPSPs. As in other types of pyramidal neuron, EPSPs evoked at $40 \mathrm{~Hz}$ summed sublinearly with the EPSP5/EPSP1 ratio between 1 and 2 (Magee, 1998, 1999; Berger et al., 2001) (Fig. 9A, red trace, D). Partially blocking Kir2 and $\mathrm{K}_{\text {leak }}$ channels with $\mathrm{Ba}^{2+}(50 \mu \mathrm{M})$ modestly depolarized the somatic membrane potential but dramatically increased the linearity of the EPSP summation (Fig. 9A, blue trace). $\mathrm{Ba}^{2+}$ increased the median EPSP5/EPSP1 ratio from $\sim 1$ 
to nearly 4 ( $n=4 ; p<0.05$, Mann-Whitney test) (Fig. 9D). Subsequent application of the HCN channel blocker ZD-7288 led to membrane hyperpolarization but little change in EPSP summation. The EPSP5/ EPSP1 ratio in the presence of ZD-7288 was not significantly different from that in the presence of $\mathrm{Ba}^{2+}$ alone $(n=4 ; p>$ 0.05, Mann-Whitney test) (Fig. 9D). Alignment of the current traces and scaling them to the first EPSP in the train show the profound impact of $\mathrm{Ba}^{2+}$ on temporal summation (Fig. 9C). Although differing in quantitative detail, these results are very similar to those obtained in the simulations arguing that $\mathrm{Kir} 2 / \mathrm{K}_{\text {leak }}$ channels are important determinants of dendritic integration.

\section{Discussion}

The studies reported here show that pyramidal neurons in the deep layers of $\mathrm{PrL} / \mathrm{IL}$ cortex coexpress $\mathrm{HCN}$, Kir2, and $\mathrm{K}_{\text {leak }}$ channels. These channels give rise to nominally antagonist ionic currents at the ambient membrane potential: one inward ( $\mathrm{HCN})$, pulling the cell toward the threshold for firing, and the others (Kir2 and $\mathrm{K}_{\text {leak }}$ ) outward, pulling the cell toward the $\mathrm{K}^{+}$equilibrium potential. The dynamic equilibrium between these currents determined the integrative properties of the dendrites.

\section{The molecular composition of PPN HCN channels endows them with the capacity to shape synaptic summation} Currents attributable to rapidly activating $\mathrm{HCN}$ channels were prominent in deeplayer PPNs. They respond to somatic, hyperpolarizing current steps with evoked voltage trajectories that possess a depolarizing sag that reaches steady state within a few hundred milliseconds at $32^{\circ} \mathrm{C}$. This sag is attributable to the activation of $\mathrm{HCN}$ channels with mixed $\mathrm{Na}^{+}$ and $\mathrm{K}^{+}$selectivity (DiFrancesco, 1981). Somatic point-clamp experiments performed in the presence of Nav1 and Kir2/KCNK channel blockers revealed a hyperpolarization-activated current that was sensitive to both $\mathrm{ZD}-7288$ and $\mathrm{Cs}^{+}$, relatively selective blockers of HCN channels (Harris and Constanti, 1995; Gasparini and DiFrancesco, 1997). The voltage dependence and kinetics of these currents were similar to those described in CA1 and neocortical pyramidal neurons at similar temperatures (Magee, 1998; Berger et al., 2001).

The electrophysiological data were in agreement with scRTPCR profiling showing that PPNs expressed high levels of HCN1 mRNA. Channels dominated by HCN1 subunits are rapidly gating and have relatively depolarized activation voltage dependence like that seen in PPNs (Franz et al., 2000; Ulens and Tytgat, 2001). However, other HCN subunit mRNAs were detected in PPNs, particularly HCN2 mRNA. The inclusion of HCN2 subunits would endow channels with a greater sensitivity to cAMP modulation (Chen et al., 2001; Wang et al., 2001). Our interpretation
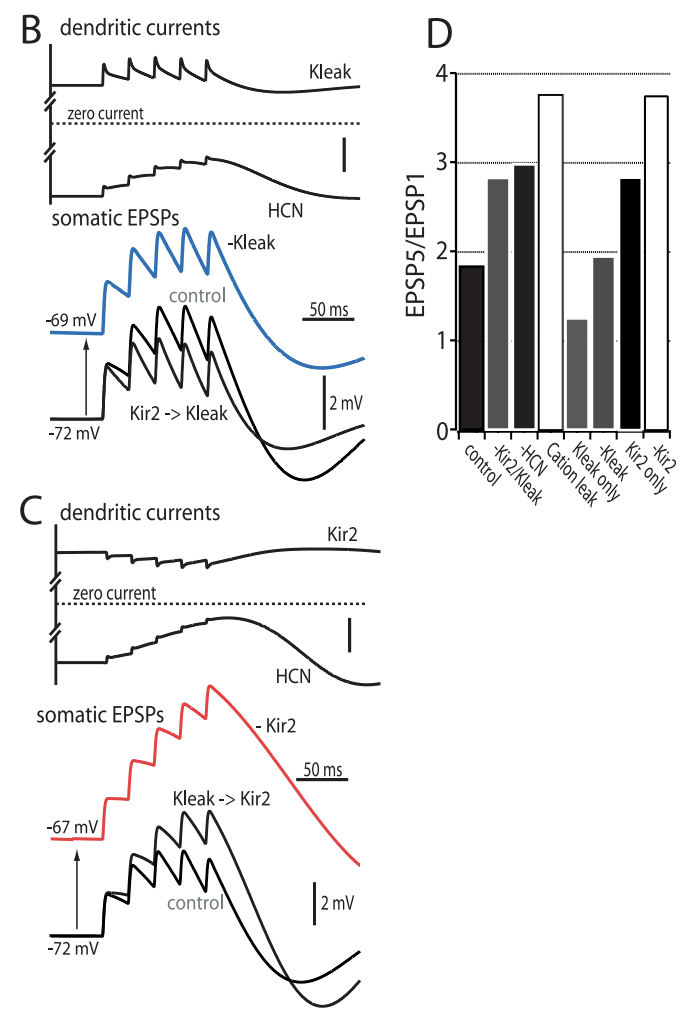

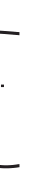

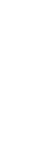
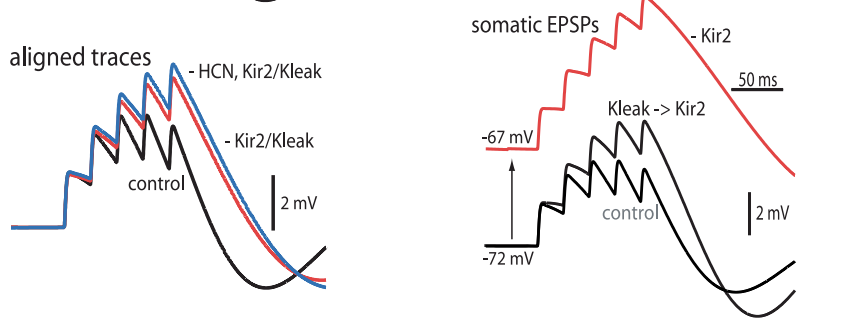

Figure 8. Simulations reducing Kir2 and $\mathrm{K}_{\text {leak }}$ channels mimic HCN blockade by reducing HCN activation. $\boldsymbol{A}$, Reducing Kir2/K $\mathrm{K}_{\text {leak }}$ channel density by $50 \%$ in the dendrites leads to membrane depolarization, deactivation of HCN channels, and greater summation

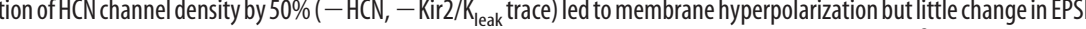
channels with $\mathrm{K}_{\text {in }}$ channels leads to more pronounced sublinearity. Top, $\mathrm{K}_{\text {ak }}$ and HCN channel currents during synaptic stimuand $\mathrm{K}_{\text {leak }}$ channels (control) and with replacement of Kir2 channels $\left(\mathrm{Kir} 2 \rightarrow \mathrm{K}_{\text {leak }}\right.$ ). Vertical scale bar, $50 \mathrm{~mA} / \mathrm{cm}^{2}$. C, Replacing K $\mathrm{K}_{\text {leak }}$ channels with Kir2 channels leads to greater EPSP summation. Top, Kir2 and HCN channel currents during synaptic stimulation. 列 channels (control) and with replacement of $K_{\text {leak }}$ channels $\left(K_{\text {leak }} \rightarrow K i r 2\right)$. Vertical scale bar, $50 \mathrm{~mA} / \mathrm{cm}^{2}$. D, Ratio of the fifth EPSP the train to the first as a function of simulation condition. Note that the ratio increases with $\mathrm{Kir} 2 / \mathrm{K}_{\text {leak }}$ reduction and changes little with subsequent HCN block. Also, summation was more sublinear with dendrites containing only $\mathrm{K}_{\text {leak }}$ channels, and the increase in summation was less than with mixed channels.

of the lower detection frequency of these mRNAs is that they are expressed at lower levels, not that there are subpopulations of PPNs. There was no evidence of kinetic variation in $\mathrm{HCN}$ channel kinetics as might be expected if there were subgroups of PPNs with different channel composition. HCN2 and HCN1 channels are capable of forming heteromultimeric channels with gating properties similar to those seen here (Chen et al., 2001; Ulens and Tytgat, 2001). The absence of a discernible slow component of the HCN current resembling HCN2 homomeric channels is consistent with the formation of heteromultimeric channels. However, we cannot exclude the possibility that channels composed of just $\mathrm{HCN} 2$ or HCN3 subunits are present, particularly in more electrotonically distant regions of the dendrite, given the spaceclamp limitations of the somatic point-clamp data.

Previous studies of HCN channels with properties like those seen in PrL/IL cortex PPNs suggest that they are important determinants of dendritic excitability. In addition to providing a depolarizing force that promotes residence of the membrane potential near the activation range of spike generating channels, HCN channels directly shape the integration of both excitatory 

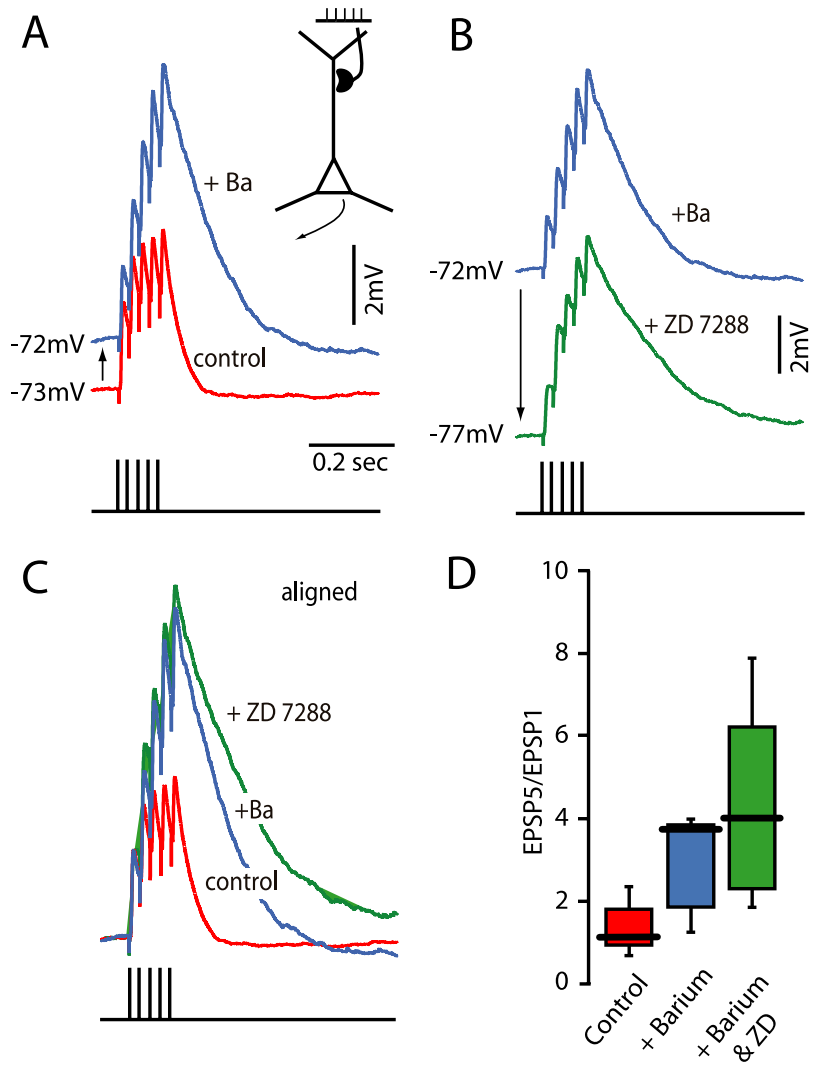

Figure 9. Kir2 and $\mathrm{K}_{\text {leak }} \mathrm{K}^{+}$-channel blockade occludes the effects of ZD-7288 on EPSP summation. $\boldsymbol{A}$, Whole-cell current-clamp records (EPSPs) from a PPN during $40 \mathrm{~Hz}, 400 \mu \mathrm{A}$ stimulation (black line) in the control condition (red trace), after partial Kir2/K $K_{\text {leak }}$ blockade after $\mathrm{Ba}^{2+}$ application (50 $\mu \mathrm{m}$, blue trace). B, EPSPs during Kir2/K $/ \mathrm{K}_{\text {leak }}$ block (blue trace in $\boldsymbol{A}$ ) and both Kir2/K $/ K_{\text {leak }}$ and HCN blockade after ZD-7288 application (50 $\mu \mathrm{m}$ each, green trace). C, Voltage traces from $\boldsymbol{A}$ and $\boldsymbol{B}$, normalized to the amplitude of the first EPSP in the train, show that the increase in temporal summation seen under conditions in which $\mathrm{Kir} 2 / \mathrm{K}_{\text {leak }}$ channels are blocked is essentially unaltered after HCN channel blockade. $D$, Box plot of the ratio of the last to first EPSP in the train illustrates that the temporal summation seen under conditions in which Kir2/ $\mathrm{K}_{\text {leak }}$ current is blocked (blue box) is not significantly increased with subsequent HCN channel blockade (green box), suggesting Kir2/K $K_{\text {leak }}$ currents are necessary to maintain HCN channel effects on synaptic integration (Mann-Whitney $U$ test; $p<0.05 ; n=4$ ).

and inhibitory synaptic events. For example, in CA1 pyramidal neurons, deactivation of HCN channels by high-frequency EPSPs creates a net outward hyperpolarizing current that leads to sublinear summation (Magee, 2000). The voltage dependence and kinetics of HCN channels in PrL/IL PPNs are consistent with a similar role, an inference supported by our Neuron simulations and direct experimental analysis.

\section{PPNs express somatodendritically positioned Kir2 inwardly rectifying $\mathrm{K}^{+}$channels}

Left to themselves, HCN channels would deactivate. The cationic current would depolarize the membrane potential, leading to closure of the hyperpolarization-activated channel. However, in the absence of prominent synaptic influences, PrL/IL PPNs "rest" well into the activation range of the HCN channels ( -65 to -70 $\mathrm{mV}$ ). Maintenance of this hyperpolarized resting potential is primarily attributable to constitutively active, inwardly rectifying Kir2 channels. This conclusion is based on several lines of evidence. First, in both current- and voltage-clamp experiments, micromolar concentrations of $\mathrm{Ba}^{2+}$ blocked an inwardly rectify- ing $\mathrm{K}^{+}$current (Takigawa and Alzheimer, 2002). Second, dialysis with the polyamine Kir2 gating molecule spermine was necessary to maintain the rectifying character of the current (Ficker et al., 1994; Fakler et al., 1995). Third, somatic point-clamp experiments suggest that the $\mathrm{Ba}^{2+}$-sensitive current gated very rapidly and reversed near the $\mathrm{K}^{+}$equilibrium potential. Fourth, in current clamp, application of $\mathrm{Ba}^{2+}$ led to membrane depolarization and the initiation of regular spiking. Fifth, scRT-PCR detected Kir2.3 and Kir2.2 mRNA transcripts in nearly all of the PPNs profiled. Immunocytochemical analysis showed that both of these subunit proteins were present throughout the somatodendritic membrane of cortical pyramidal neurons, in agreement with the recent results of Pruss et al. (2005).

Although primarily dependent on Kir2 channels, $\mathrm{KCNK} \mathrm{K}^{+}$ leak channels also are likely to contribute to the $\mathrm{Ba}^{2+}$-sensitive current. The absence of a clear negative slope conductance region in the current blocked by $200 \mu \mathrm{M} \mathrm{Ba}{ }^{2+}$ suggests that $\mathrm{K}^{+}$selective, leak channels are contributing to the current-voltage relationship. KCNK channels are blocked by $\mathrm{Ba}^{2+}$, are $\mathrm{K}^{+}$selective, and have a linear current-voltage relationship (Goldstein et al., 2001). Neuron simulations showed that uniformly distributed mixture (conductance ratio of 10:1, $G_{\text {Kir2 }} / G_{\text {Kleak }}$ ) of rectifying Kir2 and linear KCNK-like $K_{\text {leak }}$ channels could reproduce the current blocked by $200 \mu \mathrm{M} \mathrm{Ba}{ }^{2+}$. This deconstruction was supported by the observation that a lower $\mathrm{Ba}^{2+}$ concentration $(50 \mu \mathrm{M})$, which should more effectively block Kir2 than KCNK channels, yielded difference currents with profiles that more closely matched those of heterologously expressed Kir2 channels (Dahlmann et al., 2004). Additional support came from RT-PCR profiling of PPNs, which detected KCNK5 [TWIK-related acidsensitive $\mathrm{K}^{+}$channel 2 (TASK2)] and KCNK9 (TASK3) transcripts. Although our work supports a functional role for these channels, additional work is needed to verify their inferred dendritic distribution, their composition, and their regulation.

\section{Functional interaction among $\mathrm{HCN}$, Kir2, and $\mathrm{K}_{\text {leak }}$ channels in synaptic integration}

Because both HCN and Kir2 channels are dendritic, they are in position to shape synaptic integration and dendritic electrogenesis. We assume that the KCNK-like, $K_{\text {leak }}$ channels have a similar distribution. The involvement of HCN channels in sublinear summation of high-frequency EPSPs has been elegantly characterized in other types of pyramidal neurons (Magee, 1999). This characterization appears fully applicable to PrL/IL pyramidal neurons. HCN channels with kinetic features like those found in PPNs participate in shaping the response to IPSPs as well (Chan et al., 2004).

The involvement of Kir2 channels in synaptic integration is less well characterized. In CA1 pyramidal neurons, inwardly rectifying $\mathrm{K}^{+}$channels (Kir2 and Kir3 channels) reduce postsynaptic glutamatergic potentials evoked from voltages near the $\mathrm{K}^{+}$ equilibrium potential (approximately $-95 \mathrm{mV}$ ) (Takigawa and Alzheimer, 2003). In this membrane potential range, Kir2 and Kir3 channels have a positive slope conductance, resulting in outward currents with modest depolarization (Fig. 7A). These outward currents should decrease EPSP amplitude and decrease the effective membrane time constant, lessening the HCN channel activation. Our results (and simulations) are in full agreement with these observations. However, in PrL/IL pyramidal neurons, the resting membrane potential is considerably more depolarized (near $-68 \mathrm{mV}$ ). In this potential range, the rectification of the Kir2 channels creates a negative slope conductance region that leads to modest net inward (not outward) currents with mem- 
brane depolarization. These net inward currents increase the effective membrane time constant, slowing EPSP decay and increasing summation (Fig. 8) (Wessel et al., 1999). The admixture of ohmic KCNK or $\mathrm{K}_{\text {leak }}$ channels (which generate outward current at all potentials above the $\mathrm{K}^{+}$equilibrium potential) appears to effectively balance the Kir2 channels, flattening the aggregate $\mathrm{K}^{+}$current-voltage relationship and effectively isolating the $\mathrm{HCN}$ channels to regulate EPSP summation. In addition, the hyperpolarizing Kir2/KCNK current kept HCN channels in a steep operating region. Both simulation and experiment showed that diminishing the aggregate $\mathrm{K}^{+}$current increased the linearity of EPSP summation by reducing $\mathrm{HCN}$ channel activation and narrowing their dynamic range.

The normal interplay among Kir2, $\mathrm{K}_{\text {leak }}$, and HCN channels in synaptic integration is likely to be dynamically regulated. The molecular composition of these channels renders them particularly susceptible to modulation by G-protein-coupled receptors (GPCRs). For example, the inclusion of HCN2 subunits endows HCN channels with an enhanced susceptibility to modulation by cAMP (DiFrancesco and Tortora, 1991; Santoro et al., 2000), potentially increasing their engagement in synaptic integration and suppression of temporal summation. In the same vein, the reliance on Kir2.3 subunits by PPNs gives them a channel with normal gating properties but a low affinity for phosphatidyl inositol diphosphate $\left(\mathrm{PIP}_{2}\right)$ and increased susceptibility to suppression by GPCRs that deplete the membrane of PIP 2 (Rohacs et al., 2003; Du et al., 2004). Although less is known about KCNK channels contributing to the $\mathrm{K}_{\text {leak }}$ currents, they also are likely targets of modulation (Goldstein et al., 2001). In this way, neuromodulators known to impact prefrontal cortex function, such as acetylcholine, dopamine, and norepinephrine, should be capable of shifting the dynamic balance between these dendritic channels, reshaping synaptic integration as a consequence. This functionality could be critical to normal "executive functions" of the prefrontal cortex and to disorders with neuromodulator determinants such as Alzheimer's disease, schizophrenia, depression, and drug abuse (Iversen, 1998; Goldman-Rakic, 1999).

\section{References}

Akins P, Surmeier DJ, Kitai ST (1990) M1 muscarinic acetylcholine receptor in cultured rat neostriatum regulates phosphoinositide hydrolysis. J Neurochem 54:266-273.

Benson DL, Isackson PJ, Gall CM, Jones EG (1992) Contrasting patterns in the localization of glutamic acid decarboxylase and $\mathrm{Ca}^{2+} /$ calmodulin protein kinase gene expression in the rat central nervous system. Neuroscience 46:825-849.

Berger T, Larkum ME, Luscher HR (2001) High I(h) channel density in the distal apical dendrite of layer $\mathrm{V}$ pyramidal cells increases bidirectional attenuation of EPSPs. J Neurophysiol 85:855-868.

Chan CS, Shigemoto R, Mercer JN, Surmeier DJ (2004) HCN2 and HCN1 channels govern the regularity of autonomous pacemaking and synaptic resetting in globus pallidus neurons. J Neurosci 24:9921-9932.

Chen S, Wang J, Siegelbaum SA (2001) Properties of hyperpolarizationactivated pacemaker current defined by coassembly of HCN1 and HCN2 subunits and basal modulation by cyclic nucleotide. J Gen Physiol 117:491-504.

Clapham DE (1998) Not so funny anymore: pacing channels are cloned. Neuron 21:5-7.

Coetzee WA, Amarillo Y, Chiu J, Chow A, Lau D, McCormack T, Moreno H, Nadal MS, Ozaita A, Pountney D, Saganich M, Vega-Saenz de Miera E, Rudy B (1999) Molecular diversity of $\mathrm{K}^{+}$channels. Ann NY Acad Sci 868:233-285.

Dahlmann A, Li M, Gao Z, McGarrigle D, Sackin H, Palmer LG (2004) Regulation of Kir channels by intracellular $\mathrm{pH}$ and extracellular $\mathrm{K}^{+}$: mechanisms of coupling. J Gen Physiol 123:441-454.

Day M, Olson PA, Platzer J, Striessnig J, Surmeier DJ (2002) Stimulation of $5-\mathrm{HT}_{2}$ receptors in prefrontal pyramidal neurons inhibits $\mathrm{Ca}_{\mathrm{v}} 1.2 \mathrm{~L}$ type
$\mathrm{Ca}^{2+}$ currents via a PLCbeta/IP3/calcineurin signaling cascade. J Neurophysiol 87:2490-2504.

DiFrancesco D (1981) A study of the ionic nature of the pace-maker current in calf Purkinje fibres. J Physiol (Lond) 314:377-393.

DiFrancesco D, Tortora P (1991) Direct activation of cardiac pacemaker channels by intracellular cyclic AMP. Nature 351:145-147.

Du X, Zhang H, Lopes C, Mirshahi T, Rohacs T, Logothetis DE (2004) Characteristic interactions with phosphatidylinositol 4,5-bisphosphate determine regulation of kir channels by diverse modulators. J Biol Chem 279:37271-37281.

Fakler B, Brandle U, Glowatzki E, Weidemann S, Zenner HP, Ruppersberg JP (1995) Strong voltage-dependent inward rectification of inward rectifier $\mathrm{K}^{+}$channels is caused by intracellular spermine. Cell 80:149-154.

Falk T, Meyerhof W, Corrette BJ, Schafer J, Bauer CK, Schwarz JR, Richter D (1995) Cloning, functional expression and mRNA distribution of an inwardly rectifying potassium channel protein. FEBS Lett 367:127-131.

Ficker E, Taglialatela M, Wible BA, Henley CM, Brown AM (1994) Spermine and spermidine as gating molecules for inward rectifier $\mathrm{K}^{+}$channels Science 266:1068-1072.

Franklin BJ, Paxinos G (1997) The mouse brain in stereotaxic coordinates. San Diego: Academic.

Franz O, Liss B, Neu A, Roeper J (2000) Single-cell mRNA expression of HCN1 correlates with a fast gating phenotype of hyperpolarizationactivated cyclic nucleotide-gated ion channels (Ih) in central neurons. Eur J Neurosci 12:2685-2693.

Fuster JM (1997) The prefrontal cortex, Ed 3. Philadelphia: Lippincott-Raven.

Gasparini S, DiFrancesco D (1997) Action of the hyperpolarizationactivated current (Ih) blocker ZD 7288 in hippocampal CA1 neurons. Pflügers Arch 435:99-106.

Goldman-Rakic PS (1999) The "psychic" neuron of the cerebral cortex. Ann NY Acad Sci 868:13-26.

Goldstein SA, Bockenhauer D, O'Kelly I, Zilberberg N (2001) Potassium leak channels and the KCNK family of two-P-domain subunits. Nat Rev Neurosci 2:175-184.

Harris NC, Constanti A (1995) Mechanism of block by ZD 7288 of the hyperpolarization-activated inward rectifying current in guinea pig substantia nigra neurons in vitro. J Neurophysiol 74:2366-2378.

Hausser M, Spruston N, Stuart GJ (2000) Diversity and dynamics of dendritic signaling. Science 290:739-744.

Hines ML, Carnevale NT (2001) NEURON: a tool for neuroscientists. The Neuroscientist 7:123-135.

Horikawa K, Armstrong WE (1988) A versatile means of intracellular labeling: injection of biocytin and its detection with avidin conjugates. J Neurosci Methods 25:1-11.

Horio Y, Morishige K, Takahashi N, Kurachi Y (1996) Differential distribution of classical inwardly rectifying potassium channel mRNAs in the brain: comparison of IRK2 with IRK1 and IRK3. FEBS Lett 379:239-243.

Iversen SD (1998) The pharmacology of memory. C R Acad Sci III 321:209-215.

Karschin C, Dissmann E, Stuhmer W, Karschin A (1996) IRK(1-3) and GIRK(1-4) inwardly rectifying $\mathrm{K}^{+}$channel mRNAs are differentially expressed in the adult rat brain. J Neurosci 16:3559-3570.

Luthi A, McCormick DA (1998) H-current: properties of a neuronal and network pacemaker. Neuron 21:9-12.

Maccaferri G, Mangoni M, Lazzari A, DiFrancesco D (1993) Properties of the hyperpolarization-activated current in rat hippocampal CA1 pyramidal cells. J Neurophysiol 69:2129-2136.

Magee J, Hoffman D, Colbert C, Johnston D (1998) Electrical and calcium signaling in dendrites of hippocampal pyramidal neurons. Annu Rev Physiol 60:327-346.

Magee JC (1998) Dendritic hyperpolarization-activated currents modify the integrative properties of hippocampal CA1 pyramidal neurons. J Neurosci 18:7613-7624.

Magee JC (1999) Dendritic lh normalizes temporal summation in hippocampal CA1 neurons. Nat Neurosci 2:508-514.

Magee JC (2000) Dendritic integration of excitatory synaptic input. Nat Rev Neurosci 1:181-190.

Magee JC, Carruth M (1999) Dendritic voltage-gated ion channels regulate the action potential firing mode of hippocampal CA1 pyramidal neurons. J Neurophysiol 82:1895-1901.

Markram H, Lubke J, Frotscher M, Roth A, Sakmann B (1997) Physiology 
and anatomy of synaptic connections between thick tufted pyramidal neurones in the developing rat neocortex. J Physiol (Lond) 500:409-440.

McCormick DA, Shu Y, Hasenstaub A (2002) Persistent activity in the prefrontal cortex in vitro: mechanisms of initiation and cessation in local networks. Soc Neurosci Abstr 28:282.5.

Notomi T, Shigemoto R (2004) Immunohistochemical localization of Ih channel subunits, $\mathrm{HCN} 1-4$, in the rat brain. J Comp Neurol 471:241-276.

Pape HC (1996) Queer current and pacemaker: the hyperpolarizationactivated cation current in neurons. Annu Rev Physiol 58:299-327.

Pruss H, Derst C, Lommel R, Veh RW (2005) Differential distribution of individual subunits of strongly inwardly rectifying potassium channels (Kir2 family) in rat brain. Brain Res Mol Brain Res, in press.

Rall W, Burke RE, Holmes WR, Jack JJ, Redman SJ, Segev I (1992) Matching dendritic neuron models to experimental data. Physiol Rev 72:S159-S186.

Rohacs T, Lopes CM, Jin T, Ramdya PP, Molnar Z, Logothetis DE (2003) Specificity of activation by phosphoinositides determines lipid regulation of Kir channels. Proc Natl Acad Sci USA 100:745-750.

Santoro B, Chen S, Luthi A, Pavlidis P, Shumyatsky GP, Tibbs GR, Siegelbaum SA (2000) Molecular and functional heterogeneity of hyperpolarizationactivated pacemaker channels in the mouse CNS. J Neurosci 20:5264-5275.

Schwindt PC, Crill WE (1995) Amplification of synaptic current by persistent sodium conductance in apical dendrite of neocortical neurons. J Neurophysiol 74:2220-2224.

Stuart G, Sakmann B (1995) Amplification of EPSPs by axosomatic sodium channels in neocortical pyramidal neurons. Neuron 15:1065-1076.

Stuart G, Spruston N (1998) Determinants of voltage attenuation in neocortical pyramidal neuron dendrites. J Neurosci 18:3501-3510.

Surmeier DJ, Bargas J, Hemmings Jr HC, Nairn AC, Greengard P (1995) Modulation of calcium currents by a D1 dopaminergic protein kinase/ phosphatase cascade in rat neostriatal neurons. Neuron 14:385-397.
Takigawa T, Alzheimer C (2002) Phasic and tonic attenuation of EPSPs by inward rectifier $\mathrm{K}^{+}$channels in rat hippocampal pyramidal cells. J Physiol (Lond) 539:67-75.

Takigawa T, Alzheimer C (2003) Interplay between activation of GIRK current and deactivation of Ih modifies temporal integration of excitatory input in CA1 pyramidal cells. J Neurophysiol 89:2238-2244.

Tkatch T, Baranauskas G, Surmeier DJ (2000) Kv4.2 mRNA abundance and A-type $\mathrm{K}^{+}$current amplitude are linearly related in basal ganglia and basal forebrain neurons. J Neurosci 20:579-588.

Ulens C, Siegelbaum SA (2003) Regulation of hyperpolarization-activated HCN channels by cAMP through a gating switch in binding domain symmetry. Neuron 40:959-970.

Ulens C, Tytgat J (2001) Functional heteromerization of HCN1 and HCN2 pacemaker channels. J Biol Chem 276:6069-6072.

Vysokanov A, Flores-Hernandez J, Surmeier DJ (1998) mRNAs for clozapine-sensitive receptors co-localize in rat prefrontal cortex neurons. Neurosci Lett 258:179-182.

Wang J, Chen S, Siegelbaum SA (2001) Regulation of hyperpolarizationactivated HCN channel gating and cAMP modulation due to interactions of $\mathrm{COOH}$ terminus and core transmembrane regions. J Gen Physiol 118:237-250.

Wang J, Chen S, Nolan MF, Siegelbaum SA (2002) Activity-dependent regulation of HCN pacemaker channels by cyclic AMP: signaling through dynamic allosteric coupling. Neuron 36:451-461.

Wessel R, Kristan Jr WB, Kleinfeld D (1999) Supralinear summation of synaptic inputs by an invertebrate neuron: dendritic gain is mediated by an “inward rectifier" K+ current. J Neurosci 19:5875-5888.

Xue T, Marban E, Li RA (2002) Dominant-negative suppression of HCN1and HCN2-encoded pacemaker currents by an engineered HCN1 construct: insights into structure-function relationships and multimerization. Circ Res 90:1267-1273. 